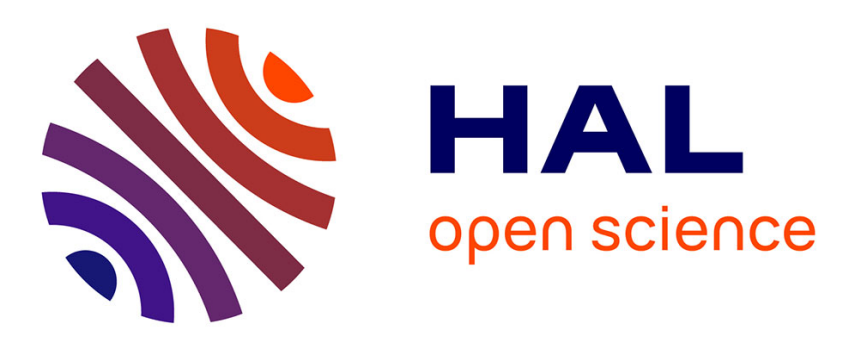

\title{
Spectral analysis for performance evaluation in a bus network
}

\author{
Ahmed Nait-Sidi-Moh, Marie-Ange Manier, Abdellah El-Moudni
}

\section{To cite this version:}

Ahmed Nait-Sidi-Moh, Marie-Ange Manier, Abdellah El-Moudni. Spectral analysis for performance evaluation in a bus network. European Journal of Operational Research, 2009, 14 p., doi:10.1016/j.ejor.2007.08.047. hal-00470040

\section{HAL Id: hal-00470040 \\ https://hal.science/hal-00470040}

Submitted on 5 Apr 2010

HAL is a multi-disciplinary open access archive for the deposit and dissemination of scientific research documents, whether they are published or not. The documents may come from teaching and research institutions in France or abroad, or from public or private research centers.
L'archive ouverte pluridisciplinaire HAL, est destinée au dépôt et à la diffusion de documents scientifiques de niveau recherche, publiés ou non, émanant des établissements d'enseignement et de recherche français ou étrangers, des laboratoires publics ou privés. 


\title{
SPECTRAL ANALYSIS FOR PERFORMANCE EVALUATION IN A BUS NETWORK
}

\author{
A. Nait-Sidi-Moh, M.-A. Manier*, A. El Moudni \\ Université de Technologie de Belfort-Montbéliard \\ Laboratoire Systèmes et Transports
}

Tel: 33 (0)384 583075 / Fax: 33 (0)384 583342

E-Mail: (ahmed.nait-sidi-moh, marie-ange.manier, abdellah.elmoudni)@utbm.fr

\begin{abstract}
This paper deals with the performance evaluation of a public transportation system in terms of waiting times at various connection points. The behaviour of a bus network is studied in the framework of Discrete Event Systems (DES). Two possible operating modes of buses can be observed at each connection stop: periodic and nonperiodic mode. Two complementary tools, Petri nets and $(\max ,+)$ algebra, are used to describe the network by a non stationary linear state model. This one can be solved after solving the structural conflicts associated to the graphical representation. From the characteristic matrix of the mathematical model, we determine eigenvalues and eigenvectors that we use to evaluate the connection times of passengers. This work is finally illustrated with a numerical example.
\end{abstract}

Keywords: Transportation Network, Petri Nets, (max, +) Algebra, Spectral theory, Performance evaluation.

\section{Introduction}

Transportation is an essential component of contemporary economics (Commission, 2001). It has to face with two contradictions: a society that expects always more mobility and a public opinion that cannot bear any more chronic delays and the poor quality of the performance of some services. Indeed, the flexibility of individual transportation modes grew for some years whereas the public transport offer is not sometimes up to the demand. This

* Corresponding author, E-mail: marie-ange.manier@utbm.fr 
partially explains the great rise of urban traffic involving more pollution and more risks of accidents.

To improve urban quality of life, one solution consists in making more attractive the collective transportation modes. It may also be promising to provide more security or more information to users or to ensure a better synchronisation between public transport vehicles (bus-bus, train-train, bus-train) so as to reduce passengers waiting times and make the displacements as fast as possible. Nevertheless, before trying to improve any performance of a collective transportation mode, it is necessary to evaluate and analyse the strength and weakness of the existing offer, so as to identify critical points of the network (connection stops on a bus network for example). Then a comparison between supply and demand will allow operators to concentrate their efforts on those critical points, and will lead to specific and more efficient actions. This second phase may be performed in a predictive planning of the system (timetabling or resources assignment), or in a real time control of the network (rescheduling in case of perturbations).

This paper deals with this first evaluation and analysis step with the purpose to improve service quality of public transport in urban centres. More precisely we consider the connection management of a bus network for which we study two possible operating modes of vehicles on the lines: in one hand, all buses perform their rounds according to a periodic timetable. On the other hand, an extension to the nonperiodic working mode is worked out. Moreover, we consider a general non synchronized behaviour of the buses which do not wait for each other at common interchange points.

Modelling, performance analysis and control of collective transportation networks are issues arousing an ever-increasing interest in many researches Olsder et al. (1998); Nait et al (2003); Houssin et al. (2006). There exist many research activities in the same field based on various modelling and analysis approaches. But most of existing works about planning and/or performance evaluation of transportation systems mainly concern railway networks in a periodic working case (Braker, 1991); Bussieck et al. (1997); De Vries et al. (1998); Olsder et al. (1998) ; Böcker et al. (2001). Such systems are synchronized ones as trains have to wait for each other so as to prevent passengers from missing their connection. Moreover, all these studies consider various criteria like punctuality and real time control rather than connection time minimization. For example De Vries et al. (1998) search for waiting times and propose robustness solutions in case of weak perturbations with the aim to evaluate consequences of delays on future connections. Olsder et al. (1998) study the improvement of initial periodic timetable for an existing network with a fixed number of trains. Some studies about bus 
networks have also been carried out. For example, Karlaftis et al. (2006) propose a decision support system for planning bus operations using mathematical programming. Houssin et al. (2006) develop a timetable synthesis using (max, +) algebra.

The work reported in this paper is a part of a more general study that aims at evaluating and controlling public transportation systems by transposing, via dioid algebra, some classical analysis and control methods from systems theory using (max, +) algebra. (Max, +) algebra is well known to be rather adapted to problems which can be modelled with event graphs, and then which suppose the absence of conflicts. Nevertheless, as it can be seen for manufacturing systems, problems related with transportation networks often come from the occurrence of phenomena like synchronization between resources and conflicts that occur when sharing of resources is necessary. Then modelling and solving the studied problem in particular involves to apply an a priori arbitrating of those ones Nait et al. (2002), or an a posteriori approach Spacek et al. (1999).

To model the studied system, we first use a subclass of Petri nets which is known as the Dynamic Timed Event Graph with Withdrawal of Tokens (DTEGWT) (David and Alla, 1992; Lahaye, 2000). It represents an adequate tool which enables one to describe the real working of the network. Indeed, this class allows us to model conflicts and synchronization, for the two considered operating modes. Then we describe the obtained model by a state representation in $(\max ,+)$ algebra, in spite of structural conflicts associated with the Petri net model. In spite of the complexity of this system, the use of dioid algebra allows us, on one hand, to obtain a linear state model and, on the other hand, to derive some properties quite easily. Besides, structural conflicts involve that the state model is expressed with a max- timeinvariant system.

In order to analyse the system and to evaluate the connection times of each passenger, we can use two approaches from the $(\max ,+)$ state representation. The first one classically consists in solving this state model Nait et al. (2005). In this paper we propose an alternative approach which avoids solving this system, and is based on spectral theory of the characteristic matrix of the $(\max ,+)$ model. It consists in determining eigenvalues and eigenvectors that enable us to evaluate the passengers waiting times.

This paper is organised as follows: in section 2, we describe the studied transportation network. In section 3, we propose a modelling of the considered bus network. In section 4, we propose a routing policy adapted to the periodic operating mode; this policy aims at arbitrating a priori the identified structural conflicts. Section 5 deals with the system performance analysis using spectral theory in dioid algebra. In section 6, we extend our study 
to the nonperiodic operating mode. In this case, another routing policy is provided to solve conflicts and spectral theory is also applied. To illustrate obtained results, a numerical example is worked out in section 7. Last section gives some conclusions and suggestions for further researches.

\section{The studied public transport system}

A bus network is composed of a set of lines which are connected by interchange points called connection stops. In a deterministic case, the evaluation of a travel performed by any passenger mainly consists in determining its connection times at each bus change and to add them to the moving times on each line from an origin point to a destination one. Then we study a part of such a bus network, which corresponds to one of such travels. It is composed of $n$ lines $(n \geq 2)$ (figure 1.). Each line $\mathrm{L}_{\mathrm{i}}$ is linked with two other lines $\mathrm{L}_{\mathrm{i}-1}$ and $\mathrm{L}_{\mathrm{i}+1}$ (except $\mathrm{L}_{1}$ and $\mathrm{L}_{\mathrm{n}}$ which only have one connection stop). $\mathrm{L}_{\mathrm{i}}$ is represented by a departure stop $\left(\mathrm{Ds}_{\mathrm{i}}\right)$, two connection stops $\mathrm{Cs}_{\mathrm{i}-1, \mathrm{i}}$ (with $\mathrm{L}_{\mathrm{i}-1}$ ) and $\mathrm{Cs}_{\mathrm{i}, \mathrm{i}+1}$ (with $\mathrm{L}_{\mathrm{i}+1}$ ), and eventually an arrival terminus $\left(\mathrm{As}_{\mathrm{i}}\right)$. Also, each line contains other simple stops that we do not consider here. Indeed, we focus on the interchange points (connection stops) that enable passengers, coming from the departure stop of line $\mathrm{L}_{1}$, to reach another stop of the line $\mathrm{L}_{\mathrm{n}}$. Let us note that we consider the passengers who take only one direction in their journey. Nevertheless the same study may be made for the passengers who take the opposite direction, and for any travel in the network.

The considered sub-network is itself composed of a set of elementary networks. Each of them contains two lines $\mathrm{L}_{\mathrm{i}}$ and $\mathrm{L}_{\mathrm{i}+1}$ connected by a common point $\mathrm{Cs}_{\mathrm{i}, \mathrm{i}+1}$.

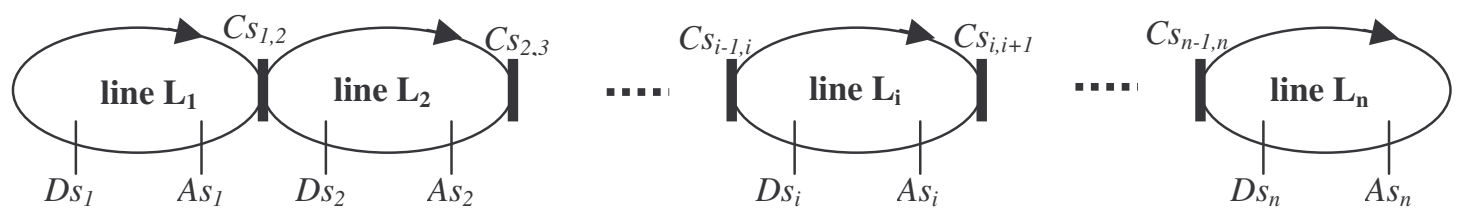

Figure 1. The physical structure of studied bus network

For each line $\mathrm{L}_{\mathrm{i}}(1 \leq \mathrm{i} \leq \mathrm{n})$, the following data are supposed to be fixed:

- the necessary time $\lambda_{\mathrm{i}}$ for a bus to perform one turn; it is the period of $\mathrm{L}_{\mathrm{i}}$ in a periodic operating mode;

- the number of buses circulating on $\mathrm{L}_{\mathrm{i}}$;

- the travel times of each bus of line $\mathrm{L}_{\mathrm{i}}$ respectively between $\mathrm{Ds}_{\mathrm{i}}$ and $\mathrm{Cs}_{\mathrm{i}, \mathrm{i}+1}$, and between $\mathrm{Cs}_{\mathrm{i}, \mathrm{i}+1}$ and $\mathrm{Ds}_{\mathrm{i}}$. Those times are respectively labelled $\tau_{\mathrm{i}, 1}$ and $\tau_{\mathrm{i}, 2}$. They include the time 
needed for passengers to go up and/or get off the bus and also the time spent at intermediate stops.

We assume that the departure of buses may be scheduled according to a periodic or nonperiodic timetable and the first starting time of each bus $B_{i}$ (bus of line $L_{i}$ ) from its departure stop $\mathrm{Ds}_{\mathrm{i}}$ is planned.

We finally suppose that all buses work independently, i.e. without synchronisation. It involves that buses of different lines do not wait for each other. Each of them leaves the connection stop just after the passengers got on/off it. It is not the same working in railway networks where synchronization is required as a train that arrives first at the connection station often has to wait for a connecting train to carry out the connection Olsder et al. (1998); De Vries et al. (1998).

In this paper, we show how spectral theory in dioid algebra may help us to evaluate travelling times. For this goal we first give graphical and mathematical formulations of the studied problem.

\section{Modelling}

\subsection{State of art}

Transportation systems can be considered as discrete event dynamic systems (DEDS) in the same level as manufacturing systems. The dynamic aspect of these systems is described by the evolution of their behaviour during a given period of time (Gaubert, 1999; Gaujal, 1994). Several studies have been made about modelling and analysis of such discrete event systems. Among the modelling tools used for these studies there are: Petri nets (David and Alla, 1992), (max, +) algebra Olsder et al. (1998); De Vries et al. (1998); Baccelli et al. (1992), Markov processes and Genetic algorithm Wang et al. (1999a, 1999b) and multi-agent approaches Böcker et al. (2005).

Transportation systems dynamics is managed with synchronization, parallelism and concurrency phenomena. So, variety of these phenomena makes the study of such systems difficult and requires the use of several complementary theories for their description and analysis. As it can be performed for flexible manufacturing systems, telecommunication networks or computer systems, we show how to adapt a Petri net and $(\max ,+)$ algebra tools to model a public transport system. Such tools have attracted the attention of many researchers: for example (Olsder et al. (1998) for planning of railway timetable using (max, +) algebra, or (Braker, 1991); De Vries et al. (1998) for performance evaluation using the same tool. 
(Gaubert, 1992) deal with the control of a transportation system by using the technique of residuation theory in $(\max ,+)$ algebra; (Di Febbraro and Sacone, 1998; Castelain and Mesghouni, 2002); Dridi et al. (2005) propose Petri nets models for transportation systems.

\subsection{Petri net model}

The behaviour of the considered network (figure 1) is represented in figure 2 by a Dynamic Timed Event Graph with Withdrawal of Tokens (DTEGWT) (Nait et al, 2005). This subclass of Petri net was first proposed in (Lahaye, 2000). In this figure, we identify $n$ circuits; each of them models one line $\mathrm{L}_{\mathrm{i}}(1 \leq \mathrm{i} \leq \mathrm{n})$. Each circuit is composed of the sequence of transitions $\left(\mathrm{x}_{\mathrm{i}, 1}, \mathrm{x}_{\mathrm{i}, 2}\right.$ or $\left.\mathrm{x}_{\mathrm{i}, 3}, \mathrm{x}_{\mathrm{i}, 4}, \mathrm{x}_{\mathrm{i}, 1}\right)$. For line $\mathrm{L}_{\mathrm{i}}$, those transitions represent specified stops: $\mathrm{x}_{\mathrm{i}, 1}$ is associated with the departure stop $\mathrm{Ds}_{\mathrm{i}} ; \mathrm{x}_{\mathrm{i}, 2}$ or $\mathrm{x}_{\mathrm{i}, 3}$ are associated with the connection stop $\mathrm{Cs}_{\mathrm{i}-1, \mathrm{i}}$; whereas $\mathrm{x}_{\mathrm{i}, 4}$ is associated with the connection stop $\mathrm{Cs}_{\mathrm{i}, \mathrm{i}+1}$. The places between those transitions represent the displacements between the associated stops. A token available on one place of a circuit represents a bus moving on the associated line. If several buses are assigned to a same line, the same number of tokens will be available on the various places of the associated circuit (this case will be more detailed in section 7). Temporisations $\tau_{i, j}(1 \leq j \leq 3)$ represent the moving times of buses on the circuit $\left(\lambda_{\mathrm{i}}=\tau_{\mathrm{i}, 1}+\tau_{\mathrm{i}, 2}+\tau_{\mathrm{i}, 3}\right)$. Places labelled $\mathrm{P}_{\mathrm{i}}$ link lines $\mathrm{L}_{\mathrm{i}}$ and $\mathrm{L}_{\mathrm{i}+1}$. They enable us to model passengers who want to carry out a connection between those two lines. Finally well transitions $o_{i}$ enable us to gather in a single batch all the passengers waiting for the same bus. Indeed such downstream transitions were added to each place $\mathrm{P}_{\mathrm{i}}$ to avoid finding several tokens in those places. Each transition $\mathrm{o}_{\mathrm{i}}$ allows a dynamic withdrawal of tokens from $\mathrm{P}_{\mathrm{i}}$ : a firing of the well transition $\mathrm{O}_{\mathrm{i}}$ is made as soon as $\mathrm{P}_{\mathrm{i}}$ contains more than one token and involves the withdrawal of these tokens. The remaining token characterizes all the passengers waiting at the connection bus stop. Adding such a downstream transition involves a structural conflict. 


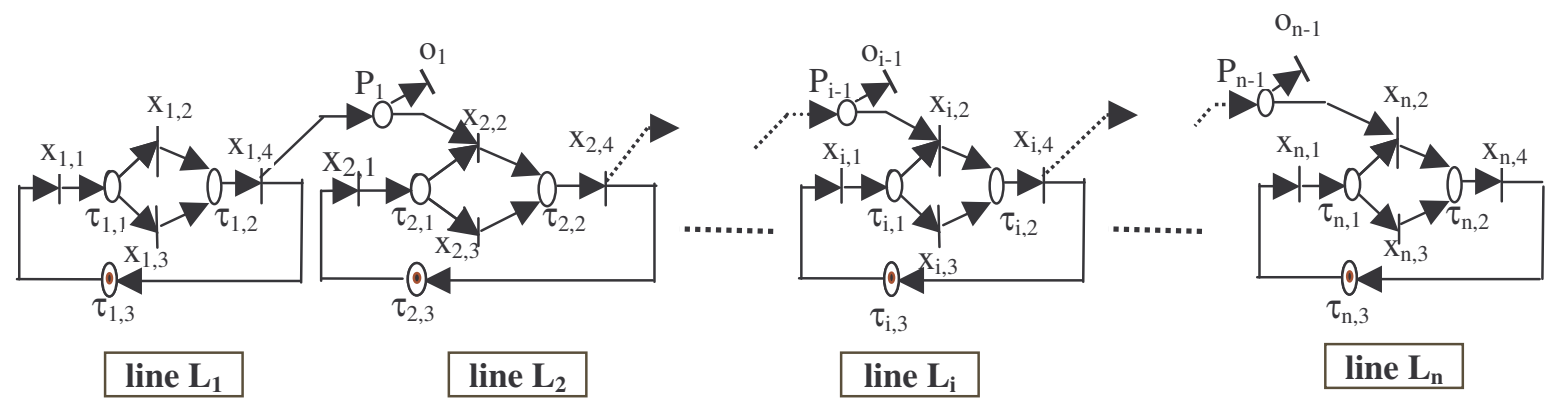

Figure 2. Petri net model of the considered bus network.

The concrete operating of buses on the network (a passenger gets/does not get on a bus at the connection stop) leads us to associate two downstream transitions $\left(\mathrm{x}_{\mathrm{i}, 2}\right.$ and $\left.\mathrm{x}_{\mathrm{i}, 3}\right)$ to some places. This situation also causes some conflicts on the Petri net model. The way to solve those conflicts depends on the operating mode of buses. In one case, we use the periodicity assumption to a priori determine a relation between the firings of upstream transitions and downstream transitions of each place Nait et al. (2002); if the buses have not a periodic operating mode we use another conflict solving method which relaxes the periodicity constraint Nait et al. (2006). In the following sections, we first study the periodic case, giving the associated $(\max ,+)$ model and its analysis based on spectral theory in order to evaluate the network performance. Then we extend our work to the nonperiodic mode.

\section{3. (Max, +$)$ formulation}

One of the mathematical approaches that we use to model our transportation system is $(\max ,+)$ algebra. All operations will be done in the dioid $\left(\mathbb{R}_{\max }, \oplus, \otimes\right)$ where “ $\oplus=$ max", “ $\otimes=+"$. The neutral elements of operators $\oplus, \otimes$ are denoted respectively $\varepsilon=-\infty$ and $\mathrm{e}=0$. More details about this algebra can be found in Baccelli et al. (1992); (Gaubert, 1992). First of all we associate the state variable $\mathrm{x}_{\mathrm{i}, \mathrm{j}}(\mathrm{k})$, called dater, with each transition $\mathrm{x}_{\mathrm{i}, \mathrm{j}}$. It represents the date of the $\mathrm{k}^{\text {th }}$ firing of transition $\mathrm{x}_{\mathrm{i}, \mathrm{j}}$. By using these daters, we obtain various equations that model the system. Because of the conflicts which appear the Petri net model, the associated $(\max ,+)$ model is a non stationary system. This means that, at a given time, the firing numbers of the downstream and upstream transitions of some places may be different from each others. 
The equations that model the considered system may be expressed in two manners according to the considered operating mode of buses and then to the associated Petri net. System (1) represents the network in the periodic case.

$$
\forall \mathrm{k} \geq 2, \begin{cases}\left(\text { Line } \mathrm{L}_{1}\right) & \mathrm{x}_{1,1}(\mathrm{k})=\tau_{1,3} \otimes \mathrm{x}_{1,4}(\mathrm{k}-1) \\ \mathrm{x}_{1,2}(\mathrm{k}) & =\varepsilon \\ \mathrm{x}_{1,3}(\mathrm{k}) & =\tau_{1,1} \otimes \mathrm{x}_{1,1}(\mathrm{k}) \\ \mathrm{x}_{1,4}(\mathrm{k}) & =\tau_{1,2} \otimes \mathrm{x}_{1,3}(\mathrm{k}) \\ \forall 2 \leq \mathrm{i} \leq \mathrm{n}, & \mathrm{x}_{\mathrm{i}, 1}(\mathrm{k})=\tau_{\mathrm{i}, 3} \otimes \mathrm{x}_{\mathrm{i}, 4}(\mathrm{k}-1) \\ \left(\text { Line } \mathrm{L}_{\mathrm{i}}\right) & \mathrm{x}_{\mathrm{i}, 2}(\mathrm{k})=\tau_{\mathrm{i}, 1} \otimes \mathrm{x}_{\mathrm{i}, 1}\left(\mathrm{k}_{\mathrm{i}, 3}\right) \oplus \mathrm{x}_{\mathrm{i}-1,4}\left(\mathrm{k}_{\mathrm{i}, 4}\right) \\ & \mathrm{x}_{\mathrm{i}, 3}(\mathrm{k})=\tau_{\mathrm{i}, 1} \otimes \mathrm{x}_{\mathrm{i}, 1}\left(\mathrm{k}_{\mathrm{i}, 6}\right) \\ \mathrm{x}_{\mathrm{i}, 4}(\mathrm{k}) & =\tau_{\mathrm{i}, 2} \otimes \mathrm{x}_{\mathrm{i}, 2}\left(\mathrm{k}_{\mathrm{i}, 7}\right) \oplus \tau_{\mathrm{i}, 2} \otimes \mathrm{x}_{\mathrm{i}, 3}\left(\mathrm{k}_{\mathrm{i}, 8}\right)\end{cases}
$$

and $\forall \mathrm{k} \geq 1$, and $\forall 1 \leq \mathrm{i} \leq \mathrm{n}-1$,

$$
\mathrm{O}_{\mathrm{i}}(\mathrm{k})=\mathrm{x}_{\mathrm{i}, 4}\left(\mathrm{k}_{\mathrm{i}, 5}\right)
$$

where: for $2 \leq \mathrm{i} \leq \mathrm{n} \begin{cases}\text { for } \mathrm{j} \in\{3,4,6\} & \mathrm{k}_{\mathrm{i}, \mathrm{j}} \geq \mathrm{k} \\ \text { for } 7 \leq \mathrm{j} \leq 8 & \mathrm{k}_{\mathrm{i}, \mathrm{j}} \leq \mathrm{k} \\ \text { for } 1 \leq \mathrm{i} \leq \mathrm{n}-1 & \mathrm{k}_{\mathrm{i}, 5} \geq \mathrm{k}\end{cases}$

Our aim is now to put system (1) in the form of a recurring equation in order to solve it. For this objective, we consider that each bus working is a periodic one. This allows us to express the firing times of any transition $\mathrm{x}_{\mathrm{i}, \mathrm{j}}$ by its anterior firing times $\left(\mathrm{x}_{\mathrm{i}, \mathrm{j}}(\mathrm{k})=\lambda_{\mathrm{i}} \otimes \mathrm{x}_{\mathrm{i}, \mathrm{j}}(\mathrm{k}-1)\right)$. By using this characteristic, system (1) becomes: $\forall \mathrm{k} \geq 2$,

$$
\mathrm{X}(\mathrm{k})=\mathrm{A}(\mathrm{k}-1) \otimes \mathrm{X}(\mathrm{k}-1)
$$

$\mathrm{X}(\mathrm{k})$ is the state vector whose components are the state variables $\mathrm{x}_{\mathrm{i}, \mathrm{j}}(\mathrm{k}) . \mathrm{X}(1)$ is the initial condition whose components are times of the first firing of each model transition (deduced from the first start time from each departure stop). $\mathrm{A}(\mathrm{k}-1)$ is given by:

$$
\mathrm{A}(\mathrm{k}-1)=\left[\begin{array}{lllll}
{\left[\mathrm{A}_{1}\right]} & & & & \\
& . . & & & \\
& & {\left[\mathrm{A}_{\mathrm{i}}\right]} & & \\
& & . . & \\
& & & {\left[\mathrm{A}_{n}\right]}
\end{array}\right]
$$


$\mathrm{A}(\mathrm{k}-1) \in \mathbb{R}_{\max }^{(4 n) \times(4 n)}$ is the characteristic matrix of the system whose elements are:

$$
\begin{aligned}
& {\left[\mathrm{A}_{\mathrm{i}}\right]=\left[\begin{array}{cccc}
\varepsilon & \varepsilon & \varepsilon & \tau_{\mathrm{i}, 3} \\
\alpha_{\mathrm{i}, 3} & \varepsilon & \varepsilon & \varepsilon \\
\alpha_{\mathrm{i}, 6} & \varepsilon & \varepsilon & \varepsilon \\
\varepsilon & \varepsilon & \varepsilon & \lambda_{\mathrm{i}}
\end{array}\right], \quad \text { for } 1 \leq \mathrm{i} \leq \mathrm{n}, \text { and }\left(\left[\mathrm{A}_{\mathrm{i}}\right]_{\mathrm{u}, \mathrm{v}}=\mathrm{A}_{4 \mathrm{i}+\mathrm{u}-4,4 \mathrm{i}+\mathrm{v}-\mathrm{i}}(\mathrm{k}-1) \text { with } \quad 1 \leq \mathrm{u}, \mathrm{v} \leq 4\right.} \\
& \mathrm{A}_{4 \mathrm{i}-2,4 \mathrm{i}-4}(\mathrm{k}-1)=\alpha_{\mathrm{i}-1,4}, \quad \text { for } 2 \leq \mathrm{i} \leq \mathrm{n} \\
& \mathrm{A}_{\mathrm{i}, \mathrm{j}}(\mathrm{k}-1)=\varepsilon \quad \text { otherwise }
\end{aligned}
$$

where: for $2 \leq \mathrm{i} \leq \mathrm{n},\left\{\begin{array}{l}\alpha_{\mathrm{i}, 3}=\alpha_{\mathrm{i}, 3}(\mathrm{k})=\tau_{\mathrm{i}, 1} \otimes \lambda_{\mathrm{i}}{ }^{(\mathrm{ki}, 3 / \mathrm{k}) \otimes 1}, \alpha_{1,3}=\alpha_{1,3}(\mathrm{k})=\varepsilon \\ \alpha_{\mathrm{i}-1,4}=\alpha_{\mathrm{i}-1,4}(\mathrm{k})=\lambda_{\mathrm{i}-1}{ }^{(\mathrm{ki}, 4 / \mathrm{k}) \otimes 1} \\ \alpha_{\mathrm{i}, 6}=\alpha_{\mathrm{i}, 6}(\mathrm{k})=\tau_{\mathrm{i}, 1} \otimes \lambda_{\mathrm{i}}{ }^{(\mathrm{ki}, 6 / \mathrm{k}) \otimes 1}\end{array}\right.$

Parameters $\mathrm{k}_{\mathrm{i}, 3}, \mathrm{k}_{\mathrm{i}, 4}$ and $\mathrm{k}_{\mathrm{i}, 6}(2 \leq \mathrm{i} \leq \mathrm{n})$ are non-constant coefficients. This characteristic is involved by the structural conflicts we have identified in the Petri net model. To solve the associated $(\max ,+)$ model, we first have to arbitrate those conflicts. It consists in expressing the above non-constant coefficients according to the variable $\mathrm{k}$.

\section{Routing equations}

To solve the conflicts associated to the PN model, we a priori determine the various relations, called routing equations, between the transition firings. We apply a periodic routing policy because of the given periodic timetable of buses. It allows us to express all the coefficients of the matrix $\mathrm{A}(\mathrm{k}-1)$ and then to solve the state representation and evaluate the various arrival times of the buses at each stop. In what follows, we give only the expression of one routing equation $k_{i+1,3}=f_{i+1,3}(k)$. Other routing equations and details about their demonstrations are given in (Nait, 2003).

$$
\begin{aligned}
& \mathrm{f}_{\mathrm{i}+1,3}(\mathrm{k})=\left[\mathrm{S}_{3, \mathrm{i}+1}(\mathrm{k}) \otimes \mathbf{1}^{\max }{ }_{\left\{\mathrm{S}_{3, i+1}(\mathrm{k}) \in \mathrm{N}\right\}} \oplus \mathrm{E}\left(\mathrm{S}_{3, \mathrm{i}+1}(\mathrm{k}) \otimes 1\right)\right. \\
&\left.\otimes \mathbf{1}^{\max }{ }_{\left\{\mathrm{S}_{3, i+1}(\mathrm{k}) \notin \mathbb{N}\right\}}\right] \otimes \mathbf{1}^{\max }{ }_{\left\{\lambda_{i}>\lambda_{i+1}\right\}} \\
& \oplus\left[\mathrm{k} \otimes \mathrm{k}_{0, i+1}^{\prime}\right] \otimes \mathbf{1}^{\max }{ }_{\left\{\lambda_{i}<\lambda_{i+1}\right\}}
\end{aligned}
$$

where:

$\mathrm{S}_{3, \mathrm{i}+1}(\mathrm{k})=\frac{\mathrm{k} \lambda_{\mathrm{i}}+\mathrm{x}_{\mathrm{i}, 4}(1)-\left(\mathrm{x}_{\mathrm{i}+1,1}(1)+\tau_{\mathrm{i}+1,1}\right)+\lambda_{\mathrm{i}+1}+\lambda_{\mathrm{i}}\left(\mathrm{k}_{0, \mathrm{i}+1}-2\right)}{\lambda_{\mathrm{i}+1}}$ and with: 
- $\mathbf{1}^{\max }\{\mathrm{a} \geq \mathrm{b}\}=\left\{\begin{array}{lc}\mathrm{e} & \text { if } \\ \varepsilon & \mathrm{a} \geq \mathrm{b}\end{array}\right.$

- $\mathrm{E}(\mathrm{x})$ the integer part of $\mathrm{x}$

- $\mathrm{k}_{0, \mathrm{i}+1}=\left\{\begin{array}{cc}1 & \text { if } \\ \sup _{\mathrm{p}} \xi_{\mathrm{i}, \mathrm{i}+1} & \text { otherwise }\end{array} \quad \xi_{\mathrm{i}, \mathrm{i}+1}=\varnothing\right.$

- $\mathrm{k}_{0, \mathrm{i}+1}=\left\{\begin{array}{ccc}0 & \text { if } & \Omega_{\mathrm{i}, \mathrm{i}+1}=\varnothing \\ \sup _{\mathrm{p}} \Omega_{\mathrm{i}, \mathrm{i}+1} & \text { otherwise } & \end{array}\right.$

$\Omega_{\mathrm{i}, \mathrm{i}+1}=\left\{\mathrm{p} \in \mathbb{N} /\left(\mathrm{x}_{\mathrm{i}+1,1}(1)+\tau_{\mathrm{i}+1,1}\right)+\lambda_{\mathrm{i}+1}(\mathrm{p}-1)<\mathrm{x}_{\mathrm{i}, 4}(1)\right\}, \xi_{\mathrm{i}, \mathrm{i}+1}=\left\{\mathrm{p} \in \mathbb{N} / \mathrm{x}_{\mathrm{i}, 4}(1)+\lambda_{\mathrm{i}}(\mathrm{p}-1)<\right.$ $\left.\mathrm{x}_{\mathrm{i}+1,1}(1)+\tau_{\mathrm{i}+1,1}\right\}$.

From the routing equations, we calculate each state of system. Then, by using these equations and the initial condition of the system $X(1)$, the solution of equation (2) is given by: $\forall \mathrm{k}>1$,

$$
\mathrm{X}(\mathrm{k})=\mathrm{A}(\mathrm{k}-1) \otimes \mathrm{A}(\mathrm{k}-2) \otimes \ldots \otimes \mathrm{A}(1) \otimes \mathrm{X}(1)
$$

\section{Analysis and evaluation of a periodic system}

Our aim is to evaluate and analyse the strength and/or weakness of an existing transport network by using spectral theory in dioid algebra. In the same context, a similar study is already achieved by using the solution of the (max, +) state model in Nait et al. (2005). The evaluation is based on temporal criteria. In the network, the travelling times of passengers directly depend on the connection times at interchange stops. Those ones can be evaluated after determining the routing equations and arbitrating all identified structural conflicts.

\subsection{Spectral theory of $A(k-1)$}

In the spectral theory, the main problem is to study the existence of eigenvalues and eigenvectors of a square matrix. In our case, we try to find these elements for the characteristic matrix $\mathrm{A}(\mathrm{k}-1)$ of the system (2). This means that we prove the existence of nonzero elements $\lambda$ and $\mathrm{V}$ such that:

$$
\mathrm{A}(\mathrm{k}-1) \otimes \mathrm{V}=\lambda \otimes \mathrm{V}
$$


For manufacturing systems, eigenvalues may be used, for example to determine the productivity of an assembly line in a periodic working mode Lahaye et al. (2000). In transportation systems, and in a periodic and synchronized case, Olsder et al. (1998); De Vries et al. (1998) use eigenvalues to identify the critical circuit of a railway network, and the associated cycle time. This one represents the minimal time between the departures of two consecutive trains (in the same given direction). An eigenvector associated with this eigenvalue corresponds to a possible vector of the first start times for trains. In the same way, we aim at interpreting those values for a urban collective transportation network, but without synchronization between vehicles.

\section{Eigenvalues}

In order to find the eigenvalues of the matrix $A(k-1)$, we use the precedence graph G(A(k-1)) Baccelli et al. (1992). The nodes of this graph are represented by the components of the state vector $X(k)$. The weight associated with each $\operatorname{arc} j \rightarrow \mathrm{i}$ represents the element $\mathrm{a}_{\mathrm{ij}}$ of $\mathrm{A}(\mathrm{k}-1)$. The research method of the eigenvalues from the precedence graph is well detailed in (Gaubert, 1992). It can be shown that every square matrix with entries in $\mathbb{R}_{\max }$ has at least one eigenvalue. If a matrix is irreducible, it has only one eigenvalue. Otherwise the number of eigenvalues of a square matrix $A$ depends on the elementary circuits $C_{i}$ of the associated precedence graph G(A(k-1)) (De Schutter, 1996); Cohen et al. (1985). Each eigenvalue of the matrix $\psi$ is calculated by: $\max _{\mathrm{c}_{\mathrm{i}}}\left(\sum_{l=1}^{r} \mathrm{w}_{l}\right) / r$, where the circuit $\mathrm{C}_{\mathrm{i}}$ is composed of $\mathrm{r} \operatorname{arcs}\left(\mathrm{a}_{1}, \mathrm{a}_{2}\right.$, $\left.\ldots, \mathrm{a}_{\mathrm{r}}\right) ; \mathrm{w}_{l}$ denotes the associated weight of each arc $\mathrm{a}_{l}$ with $1 \leq l \leq 4$.

Figure 3 provides the precedence graph we obtained in the periodic operating mode. From this graph, we easily deduce the following set of $\mathrm{n}$ associated eigenvalues: $\operatorname{Sp}(\mathrm{A}(\mathrm{k}-1))=\left\{\lambda_{1}, \lambda_{2}, \ldots, \lambda_{\mathrm{n}}\right\}$. These eigenvalues represent the periods $\lambda_{\mathrm{i}}$ of the studied bus lines. They do not depend on variable $\mathrm{k}$. Moreover, even if we study a matrix with nonconstant coefficients, its eigenvalues are constant.
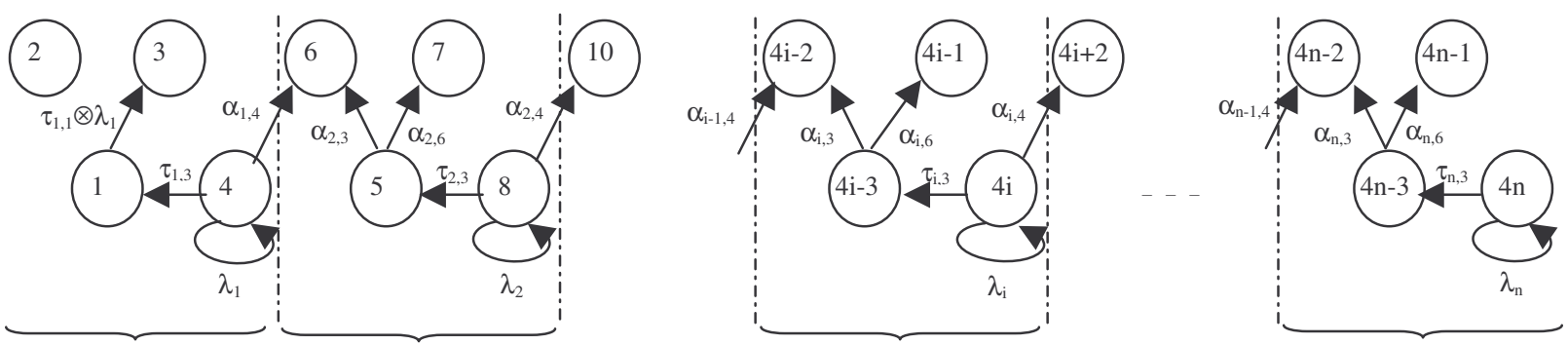
Figure 3. Precedence graph of the matrix A(k-1).

\section{Eigenvectors}

In this section we determine the eigenvectors $V^{\lambda_{i}}$ associated with each eigenvalue $\lambda_{i}(1 \leq i \leq n)$ of the characteristic matrix $A(k-1)$. Any vector $\mathrm{V}^{\lambda_{i}} \in \mathbb{R}_{\max }^{(4 n) x 1}$ and satisfies system (5).

$$
\mathrm{A}(\mathrm{k}-1) \otimes \mathrm{V}^{\lambda_{\mathrm{i}}(\mathrm{k})}=\lambda_{\mathrm{i}} \otimes \mathrm{V}^{\lambda_{\mathrm{i}}}(\mathrm{k})
$$

By developing this system, we obtain all components of the vector $\mathrm{V}^{\lambda_{i}}=\left[\mathrm{v}_{1,1}^{\lambda_{\mathrm{i}}}, \mathrm{v}_{1,2}^{\lambda_{\mathrm{i}}}, \mathrm{v}_{1,3}^{\lambda_{\mathrm{i}}}\right.$, $\left.v_{1,4}^{\lambda_{i}}, \ldots, v_{n, 1}^{\lambda_{i}}, v_{n, 2}^{\lambda_{i}}, v_{n, 3}^{\lambda_{i}}, v_{n, 4}^{\lambda_{i}}\right]^{t}$. So, we obtain for each $\lambda_{i} \in \operatorname{Sp}(A(k-1))$ :

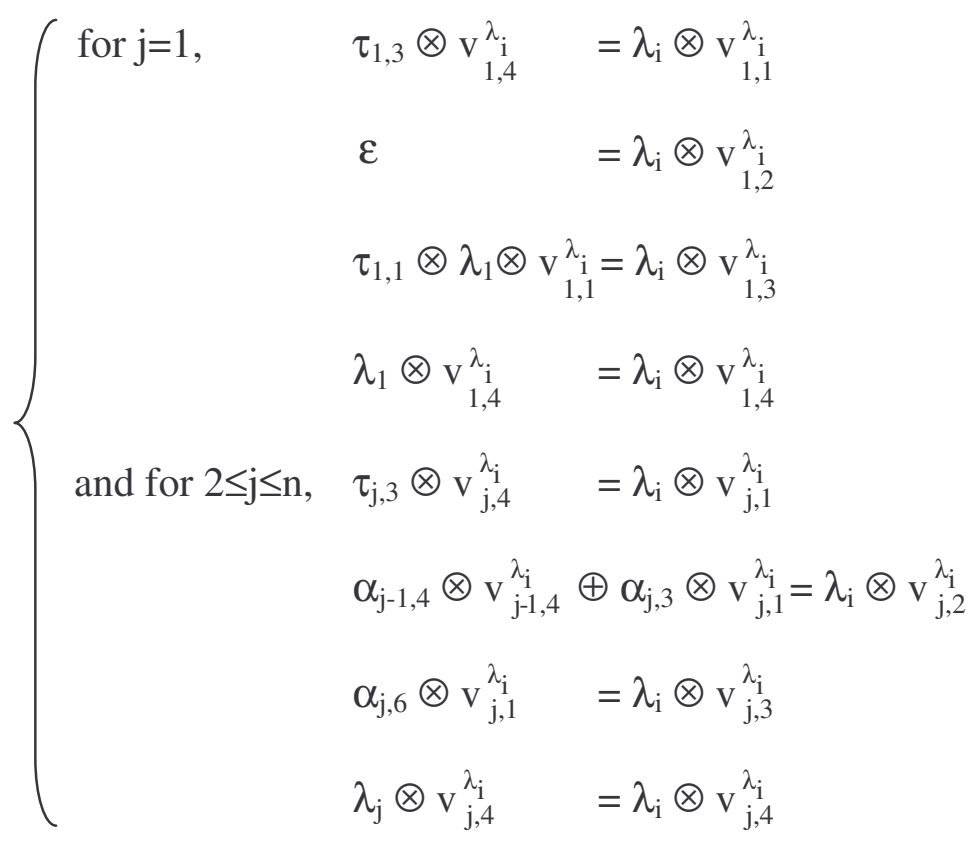

which gives the following eigenvectors:

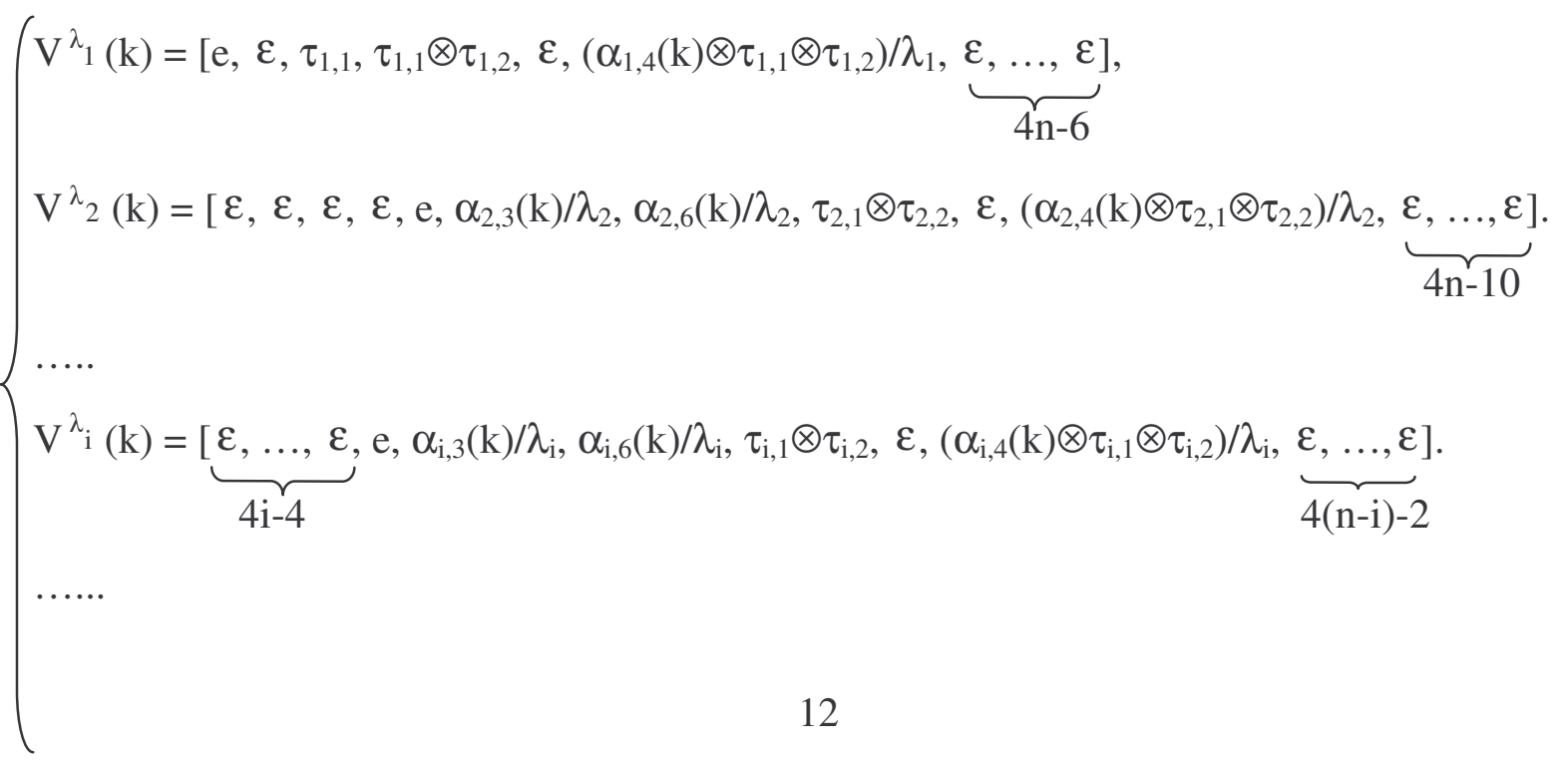




$$
\mathrm{V}^{\lambda} \mathrm{n}(\mathrm{k})=[\underbrace{\varepsilon, \ldots, \varepsilon}_{4 \mathrm{n}-4}, \mathrm{e}, \alpha_{\mathrm{n}, 3}(\mathrm{k}) / \lambda_{\mathrm{n}}, \alpha_{\mathrm{n}, 6}(\mathrm{k}) / \lambda_{\mathrm{n}}, \tau_{\mathrm{n}, 1} \otimes \tau_{\mathrm{n}, 2}]
$$

A first analyse leads us to the following remark: for each $\mathrm{V}^{\lambda_{i}}$, all components are null (equal to $\varepsilon$ ) except $v_{i, 1}^{\lambda_{i}}, v_{i, 2}^{\lambda_{i}}, v_{i, 3}^{\lambda_{i}}, v_{i, 4}^{\lambda_{i}}$ and $v_{i+1,2}^{\lambda_{i}}$. In the state vector, those ones correspond to the positions of $\mathrm{x}_{\mathrm{i}, 1}, \mathrm{x}_{\mathrm{i}, 2}, \mathrm{x}_{\mathrm{i}, 3}, \mathrm{x}_{\mathrm{i}, 4}$ (transitions associated with the line $\mathrm{L}_{\mathrm{i}}$ ) and $\mathrm{x}_{\mathrm{i}+1,2}$ (transition associated with the connection stop $\left.\mathrm{Cs}_{\mathrm{i}, \mathrm{i}+1}\right)$.

In what follows, we analyse the components of these eigenvectors.

\subsection{Identification of the eigenvectors $V^{\lambda_{i}}$}

We give below other equivalent expressions of components $v_{i, 1}^{\lambda_{i}}, v_{i, 2}^{\lambda_{i}}, v_{i, 3}^{\lambda_{i}}, v_{i, 4}^{\lambda_{i}}$ and $v_{i+1,2}^{\lambda_{i}}$, $\forall \mathrm{V}^{\lambda_{i}}$. They depend on the components of the state vector.

$\mathrm{v}_{\mathrm{j}, \mathrm{r}}^{\lambda_{\mathrm{i}}}(\mathrm{k})= \begin{cases}\mathrm{x}_{\mathrm{j}, \mathrm{r}}(\mathrm{k})-\mathrm{x}_{\mathrm{j}, 1}(\mathrm{k}), & \text { if } \mathrm{j}=\mathrm{i} \text { and } 1 \leq \mathrm{r} \leq 4 \\ \left(\mathrm{x}_{\mathrm{i}+1,2}(\mathrm{k})-\mathrm{x}_{\mathrm{i}, 1}(\mathrm{k})\right)-\left(\mathrm{x}_{\mathrm{i}+1,2}(\mathrm{k})-\mathrm{x}_{\mathrm{i}, 4}(\mathrm{~m})\right) & \text { if } \mathrm{j}=\mathrm{i}+1, \text { and } \mathrm{r}=2(\text { with } \mathrm{i}<\mathrm{n}) \\ \varepsilon & \text { otherwise }\end{cases}$

with $m=\sup _{j}\left\{j \in \mathbb{N} / x_{i+1,2}(k) \geq x_{i, 4}(j)\right\}$.

If $\mathrm{i}=\mathrm{n}$, the second equation of (8) will not be considered, because the network is only composed of $n$ lines (i.e. there exists no connection $\mathrm{Cs}_{\mathrm{n}, \mathrm{n}+1}$ ). The components of system (8) depend on the arrival times of buses at various stops of the line $\mathrm{L}_{\mathrm{i}}$. Indeed they are expressed according to the firing times of transitions $\mathrm{x}_{\mathrm{i}, 1}, \mathrm{x}_{\mathrm{i}, 2}, \mathrm{x}_{\mathrm{i}, 3}, \mathrm{x}_{\mathrm{i}, 4}$, and even $\mathrm{x}_{\mathrm{i}+1,2}$ associated with the common stop $\mathrm{Cs}_{\mathrm{i}, \mathrm{i}+1}$. In the second equation of system (8) the expression " $\mathrm{x}_{\mathrm{i}+1,2}(\mathrm{k})-\mathrm{x}_{\mathrm{i}, 4}(\mathrm{~m})$ " represents exactly the waiting time of passengers coming on the $\mathrm{m}^{\text {th }}$ bus $\mathrm{B}_{\mathrm{i}}$ that arrives at the connection stop $\mathrm{Cs}_{\mathrm{i}, \mathrm{i}+1}$ at time $\mathrm{x}_{\mathrm{i}, 4}(\mathrm{~m})$, just before the arrival of the $\mathrm{k}^{\text {th }}$ bus $\mathrm{B}_{\mathrm{i}+1}$ at time $\mathrm{x}_{\mathrm{i}+1,2}(\mathrm{k})$. We put then: for $1 \leq \mathrm{i} \leq \mathrm{n}$,

$$
\begin{aligned}
& \mathrm{T}_{\mathrm{i}, \mathrm{i}+1}(\mathrm{~m}, \mathrm{k})=\mathrm{x}_{\mathrm{i}+1,2}(\mathrm{k})-\mathrm{x}_{\mathrm{i}, 4}(\mathrm{~m}) \quad \text { in the usual algebra } \\
& =\mathrm{x}_{\mathrm{i}+1,2}(\mathrm{k}) / \mathrm{x}_{\mathrm{i}, 4}(\mathrm{~m}) \text { in the }(\max ,+) \text { algebra }
\end{aligned}
$$

By introducing this expression in the second equation of the system (8) we can write: 


$$
\begin{aligned}
\underset{\mathrm{i}+1,2}{\mathrm{i}_{\mathrm{i}}}(\mathrm{k}) & =\left(\mathrm{x}_{\mathrm{i}+1,2}(\mathrm{k})-\mathrm{x}_{\mathrm{i}, 1}(\mathrm{k})\right)-\left(\mathrm{x}_{\mathrm{i}+1,2}(\mathrm{k})-\mathrm{x}_{\mathrm{i}, 4}(\mathrm{~m})\right) \\
= & \mathrm{x}_{\mathrm{i}+1,2}(\mathrm{k})-\mathrm{x}_{\mathrm{i}+1,1}(\mathrm{k})+\mathrm{x}_{\mathrm{i}+1,1}(\mathrm{k})-\mathrm{x}_{\mathrm{i}, 1}(\mathrm{k})-\mathrm{T}_{\mathrm{i}, \mathrm{i}+1}(\mathrm{~m}, \mathrm{k}) \\
= & \mathrm{v}_{\mathrm{i}+1,2}^{\lambda_{\mathrm{i}+1}}(\mathrm{k})+\mathrm{x}_{\mathrm{i}+1,1}(\mathrm{k})-\mathrm{x}_{\mathrm{i}, 1}(\mathrm{k})-\mathrm{T}_{\mathrm{i}, \mathrm{i}+1}(\mathrm{~m}, \mathrm{k})
\end{aligned}
$$

This implies that:

$$
\mathrm{T}_{\mathrm{i}, \mathrm{i}+1}(\mathrm{~m}, \mathrm{k})=\left[\mathrm{v}_{\mathrm{i}+1,2}^{\lambda_{\mathrm{i}+1}}(\mathrm{k})-\mathrm{v}_{\mathrm{i}+1,2}^{\lambda_{\mathrm{i}}}(\mathrm{k})\right]+\left[\mathrm{x}_{\mathrm{i}+1,1}(\mathrm{k})-\mathrm{x}_{\mathrm{i}, 1}(\mathrm{k})\right]
$$

In this expression, the parameter $\mathrm{k}$ is calculated according to $\mathrm{m}$ in the following way:

$$
\mathrm{k}=\inf _{l}\left\{l \in \mathbb{N} / \mathrm{x}_{\mathrm{i}+1,2}(l) \geq \mathrm{x}_{\mathrm{i}, 4}(\mathrm{~m})\right\}
$$

Then a relation has been established between the waiting time of some passengers and the components of the eigenvectors. Nevertheless, in particular cases, some waiting times cannot be calculated with the spectral theory. These cases occur both if $\lambda_{i}<\lambda_{i+1}$ and if $b$ batches of passengers successively arrive on buses $B i$ of line $L_{i}$ (the $j^{\text {th }}, j+1^{\text {th }}, \ldots j+b-1^{\text {th }}$ arrivals) between two arrivals of buses of line $\mathrm{L}_{\mathrm{i}+1}\left(\mathrm{k}-1^{\text {th }}\right.$ and $\mathrm{k}^{\text {th }}$ ones). Then the parameter $\mathrm{m}$ defined in (8) equals $\mathrm{j}+\mathrm{b}-1$ (last arrival of passengers aiming at boarding the $\mathrm{k}^{\text {th }}$ bus $\mathrm{B}_{\mathrm{i}+1}$ ). Then the expression (8) of the associated eigenvector only considers this batch among the $b$ ones. Consequently the proposed method only enables us to define the waiting time of the last batch arriving at the connection stop. In the other cases (if $\lambda_{i} \geq \lambda_{i+1}$ ), the spectral theory enables us to calculate the waiting times of all passengers who make a connection at stop $\mathrm{Cs}_{\mathrm{i}, \mathrm{i}+1}$.

In general case, the waiting time for a passenger who arrives at time $t$ at the stop $\mathrm{Ds}_{\mathrm{i}}$ and who wants to reach a stop of the line $\mathrm{L}_{\mathrm{j}}$ is given by:

For $1 \leq \mathrm{i}<\mathrm{j} \leq \mathrm{n}, \mathrm{T}_{\mathrm{wait}}(\mathrm{i}, \mathrm{j}, \mathrm{t})=\sum_{l=i}^{j-1} \mathrm{~T}_{l, l+1}\left(\mathrm{k}_{l}, \mathrm{k}_{l+1}\right)$

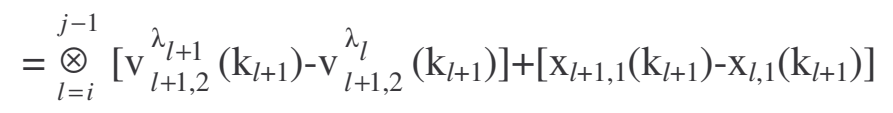

where $\mathrm{k}_{l}=\inf _{\mathrm{h}}\left\{\mathrm{h} \in \mathrm{N} / \mathrm{x}_{l, 1}(\mathrm{~h}) \geq \mathrm{t}\right\}$, and $\mathrm{k}_{l+1}=\inf _{\mathrm{h}}\left\{\mathrm{h} \in \mathrm{N} / \mathrm{x}_{l+1,2}(\mathrm{~h}) \geq \mathrm{x}_{l, 4}\left(\mathrm{k}_{l}\right)\right\}$

Besides the moving time of a passenger from $\mathrm{Ds}_{\mathrm{i}}$ to $\mathrm{As}_{\mathrm{j}}$ is given by: for $1 \leq \mathrm{i}<\mathrm{j} \leq \mathrm{n}$,

$$
\left\{\begin{aligned}
\mathrm{T}_{\text {moving }}(\mathrm{i}, \mathrm{j}, \mathrm{t}) & =\tau_{\mathrm{i}, 1} \otimes \tau_{\mathrm{i}, 2} \otimes \tau_{\mathrm{i}+1,2} \otimes \tau_{\mathrm{i}+2,2} \otimes \ldots \otimes \tau_{\mathrm{j}-1,2} \otimes \mathrm{d}_{\mathrm{j}} \\
& =\tau_{\mathrm{i}, 1} \otimes\left({ }_{l=i} \otimes \tau_{1,2}\right) \otimes \mathrm{d}_{\mathrm{j}} \\
\mathrm{T}_{\text {moving }}(\mathrm{i}, \mathrm{i}, \mathrm{t}) & =\mathrm{d}_{\mathrm{i}}
\end{aligned}\right.
$$

where: 
- $\tau_{\mathrm{i}, 1} \otimes \tau_{\mathrm{i}, 2}$ is the time necessary to join $\mathrm{Cs}_{\mathrm{i}, \mathrm{i}+1}$ from the departure stop $\mathrm{Ds}_{\mathrm{i}}$;

- $\tau_{\mathrm{u}, 2}(\mathrm{i}<\mathrm{u}<\mathrm{j})$ is the moving time between the two connection stops $\mathrm{Cs}_{\mathrm{u}-1, \mathrm{u}}$ and $\mathrm{Cs}_{\mathrm{u}, \mathrm{u}+1}$ of the line $\mathrm{L}_{\mathrm{u}}(1<\mathrm{U}<\mathrm{n})$;

$-d_{j}(1 \leq j \leq n)$ is the moving time between:

- the stop where the passenger boards the bus $B_{j}$ (if $i<j$, it is the connection stop $\mathrm{Cs}_{\mathrm{j}-1, \mathrm{j}}$; if $\mathrm{i}=\mathrm{j}$, it is the departure stop $\mathrm{Ds}_{\mathrm{j}}$ ),

- and the stop $\mathrm{As}_{\mathrm{j}}$ of the line $\mathrm{L}_{\mathrm{j}}$ that represents the destination of the passenger.

The total time spent by the considered passenger on travelling from $\mathrm{L}_{\mathrm{i}}$ to $\mathrm{L}_{\mathrm{j}}$, while making the connections $\mathrm{Cs}_{\mathrm{i}, \mathrm{i}+1}, \ldots, \mathrm{Cs}_{\mathrm{j}-1, \mathrm{j}}$, is then : for $1 \leq \mathrm{i}<\mathrm{j} \leq \mathrm{n}$,

$$
\left\{\begin{aligned}
\mathrm{T}_{\text {journey }}(\mathrm{i}, \mathrm{j}, \mathrm{t}) & =\mathrm{T}_{\text {wait }}(\mathrm{i}, \mathrm{j}, \mathrm{t}) \otimes \mathrm{T}_{\text {moving }}(\mathrm{i}, \mathrm{j}, \mathrm{t}) \\
& ={ }_{l=i}^{j-1} \mathrm{~T}_{l, l+1}\left(\mathrm{k}_{l}, \mathrm{k}_{l+1}\right) \otimes \tau_{\mathrm{i}, 1} \otimes\left(\stackrel{(}{l=i}^{j-1} \tau_{l, 2}\right) \otimes \mathrm{d}_{\mathrm{j}} \\
\mathrm{T}_{\text {journey }}(\mathrm{i}, \mathrm{i}, \mathrm{t}) & =\mathrm{e} \otimes \mathrm{T}_{\text {moving }}(\mathrm{i}, \mathrm{i}, \mathrm{t})=\mathrm{e} \otimes \mathrm{d}_{\mathrm{i}}=\mathrm{d}_{\mathrm{i}}
\end{aligned}\right.
$$

These results depend on the $\mathrm{k}_{\mathrm{i}}^{\text {th }}$ bus on which passengers will get at the stop Ds $\mathrm{s}_{\mathrm{i}}$ of the line $\mathrm{L}_{\mathrm{i}}$. Indeed the waiting time of a passenger travelling on one part of a network depends on the departure time of the buses, number of buses, frequencies ...

\section{Extension to nonperiodic operating mode}

\subsection{Modelling}

If we relax the periodicity constraint, solving the model (1) is not feasible any more. So to study the system in a non periodic working mode and to solve the identified structural conflicts, we propose a state representation that can be deduced from a new Petri net model. In this case a conflict solving semantics must be found which prevents the deadlock in the graphical representation, and which allows a detailed analysis so as to optimize the network dynamics.

Let us consider again an elementary network composed of two lines $\mathrm{L}_{\mathrm{i}}$ and $\mathrm{L}_{\mathrm{i}+1}$. The modelling technique that we use for this network is detailed in Nait et al. (2006). For each place $\mathrm{P} \in \mathrm{P}_{\text {conf }}$ ( set of places in conflict situation, $\left|\mathrm{P}^{\bullet}\right|>1$ ) and with each transition $\mathrm{t} \in \mathrm{P}^{\bullet}$, we associate a routing function defined by:

$$
\Delta_{\mathrm{t}}: \mathbb{N}^{*} \rightarrow\{\mathrm{e}, \varepsilon\}
$$




$$
\mathrm{k} \mapsto \Delta_{\mathrm{t}}(\mathrm{k})
$$

- $\Delta_{\mathrm{t}}(\mathrm{k})=\mathrm{e}$, implies that the transition $\mathrm{t}$ is fired by the $\mathrm{k}^{\text {th }}$ token arriving in $\mathrm{P}$.

- $\Delta_{\mathrm{t}}(\mathrm{k})=\varepsilon$, implies that the transition $\mathrm{t}$ will not be fired by the $\mathrm{k}^{\text {th }}$ token arriving in $\mathrm{P}$. This token takes part in the firing of another transition $\mathrm{t}^{\prime} \in \mathrm{P}^{\bullet}$.

This technique allows each model transition $\mathrm{t} \in \mathrm{P}^{\bullet}$ to be fired effectively (if $\Delta_{\mathrm{t}}(\mathrm{k})=\mathrm{e}$ ) or virtually (if $\Delta_{\mathrm{t}}(\mathrm{k})=\varepsilon$ ) if a token is present in $\mathrm{P}^{\bullet}$. It can be seen like another technique to solve the identified structural conflicts. In the graph of figure 2, it consists in associating two routing functions $\Delta \mathrm{x}_{\mathrm{i}, 2}(\mathrm{k})$ and $\Delta \mathrm{x}_{\mathrm{i}, 3}(\mathrm{k})$ respectively to transitions $\mathrm{x}_{\mathrm{i}, 2}$ and $\mathrm{x}_{\mathrm{i}, 3}$ of each circuit. Also, we associate to some arcs a weight $\mathrm{m}(\mathrm{P})$ (number of tokens presented in $\mathrm{P}$ ) which may be different from 1. This means that all batches of passengers waiting at a connection stop represented by place $\mathrm{P}$ get on the same bus and carry out the connection. The weight $\mathrm{m}\left(\mathrm{P}_{\mathrm{i}}\right)$ on the connecting arc replaces the output transition $\mathrm{o}_{\mathrm{i}}$ in figure 2 . By applying this technique to an elementary network $\left(\mathrm{L}_{\mathrm{i}}, \mathrm{L}_{\mathrm{i}+1}\right)$, the obtained Petri net model is given by figure 4 . To model the non periodic working mode of network we also add input transitions $u_{i}$ and $u_{i+1}$ to this Petri net. So it is possible to act on these inputs to advance or delay a bus departure.

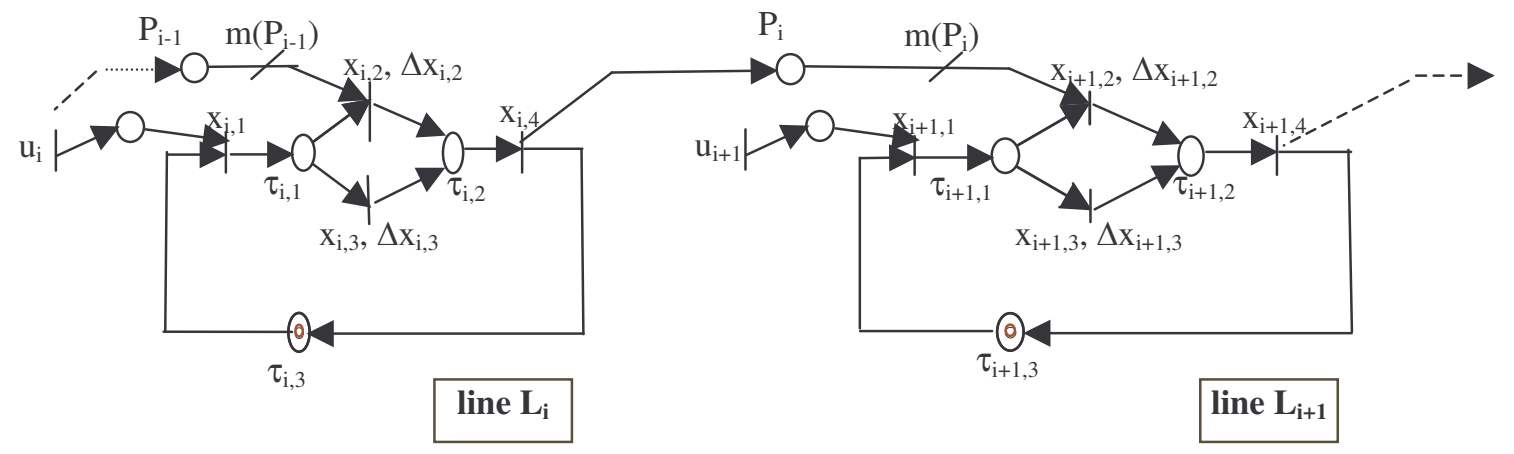

Figure 4. Petri net model of an elementary network for a non periodic mode.

Hereafter we give the expression of each dater $x_{i, j}(k)$. For example we consider $x_{i, 2}(k)$. For all $\mathrm{k} \geq 1$,

$$
\begin{aligned}
\mathrm{x}_{\mathrm{i}, 2}(\mathrm{k}) & =\mathrm{x}_{\mathrm{i}-1,4}\left(\mathrm{k}_{1}\right) \otimes \Delta \mathrm{x}_{\mathrm{i}, 2}(\mathrm{k}) \oplus \tau_{\mathrm{i}, 1} \otimes \mathrm{x}_{\mathrm{i}, 1}(\mathrm{k}) \otimes \Delta \mathrm{x}_{\mathrm{i}, 2}(\mathrm{k}) \\
& =\mathrm{x}_{\mathrm{i}, 1}(\mathrm{k}) \otimes \Delta \mathrm{x}_{\mathrm{i}, 2}(\mathrm{k})
\end{aligned}
$$

where $\mathrm{k}_{1}=\mathrm{f}\left(\mathrm{m}\left(\mathrm{P}_{\mathrm{i}}\right)\right)$. 
The connection will be done just when a bus $\mathrm{B}_{\mathrm{i}+1}$ arrives at the connection stop $\mathrm{Cs}_{\mathrm{i}, \mathrm{i}+1}$. So the arrival time of this bus is larger than the arrival times of all passengers who board it. Then one can deduce, for all $\mathrm{k} \geq 1, \mathrm{x}_{\mathrm{i}, 1}(\mathrm{k}) \geq \mathrm{x}_{\mathrm{i}-1,4}\left(\mathrm{k}_{1}\right)$. In the same way, we obtain all equations of the model:

$\forall \mathrm{k}>1, \forall \mathrm{j}, \quad 1 \leq \mathrm{j} \leq \mathrm{n}$,

$$
\left\{\begin{array}{l}
\mathrm{x}_{\mathrm{j}, 1}(\mathrm{k})=\tau_{\mathrm{j}, 3} \otimes \mathrm{x}_{\mathrm{j}, 4}(\mathrm{k}-1) \oplus \mathrm{u}_{\mathrm{j}}(\mathrm{k}) \\
\mathrm{x}_{\mathrm{j}, 2}(\mathrm{k})=\tau_{\mathrm{j}, 1} \otimes \mathrm{x}_{\mathrm{j}, 1}(\mathrm{k}) \otimes \Delta \mathrm{x}_{\mathrm{j}, 2}(\mathrm{k}) \\
\mathrm{x}_{\mathrm{j}, 3}(\mathrm{k})=\tau_{\mathrm{j}, 1} \otimes \mathrm{x}_{\mathrm{j}, 1}(\mathrm{k}) \otimes \Delta \mathrm{x}_{\mathrm{j}, 3}(\mathrm{k}) \\
\mathrm{x}_{\mathrm{j}, 4}(\mathrm{k})=\tau_{\mathrm{j}, 1} \otimes \tau_{\mathrm{j}, 2} \otimes \mathrm{x}_{\mathrm{j}, 1}(\mathrm{k})
\end{array}\right.
$$

(14) is an implicit system. The explicit matrix form of (14) can be expressed by: $\forall \mathrm{k}>1$,

$$
\begin{aligned}
\mathrm{X}(\mathrm{k}) & =\mathrm{A}_{0} \Delta(\mathrm{k}) \mathrm{X}(\mathrm{k}) \oplus \mathrm{A}_{1} \mathrm{X}(\mathrm{k}-1) \oplus \mathrm{B} \mathrm{U}(\mathrm{k}) \\
& =\left(\mathrm{A}_{0} \Delta(\mathrm{k})\right)^{*} \mathrm{~A}_{1} \mathrm{X}(\mathrm{k}-1) \oplus\left(\mathrm{A}_{0} \Delta\right)^{*} \mathrm{~B} \mathrm{U}(\mathrm{k}) \\
& =\mathrm{M} \mathrm{X}(\mathrm{k}-1) \oplus \mathrm{N} \mathrm{U}(\mathrm{k})
\end{aligned}
$$

where $\mathrm{X}(\mathrm{k}) \in \mathbb{R}_{\max }^{4 n}, \mathrm{M}=\left(\mathrm{A}_{0} \Delta(\mathrm{k})\right)^{*} \mathrm{~A}_{1} \in \mathbb{R}_{\max }^{4 n x 4 n}$ and $\mathrm{N}=\left(\mathrm{A}_{0} \Delta(\mathrm{k})\right)^{*} \mathrm{~B} \in \mathbb{R}_{\max }^{4 n x 2} \cdot \Delta(\mathrm{k})=\mathbb{R}_{\max }^{4 n x 4 n}$ is the routing matrix whose components are the routing functions $\Delta \mathrm{x}_{\mathrm{i}, \mathrm{j}}(\mathrm{k})$ for all $\mathrm{k} .\left(\mathrm{A}_{0} \Delta(\mathrm{k})\right)^{*}$ is the Kleene star of $\left[\mathrm{A}_{0} \Delta(\mathrm{k})\right]$ which is defined by $\left(\mathrm{A}_{0} \Delta(\mathrm{k})\right)^{*}=\mathrm{Id} \oplus \mathrm{A}_{0} \Delta(\mathrm{k}) \oplus\left(\mathrm{A}_{0} \Delta(\mathrm{k})\right)^{2} \oplus$ ...., Matrix $\mathrm{M}$ is made of blocs $\left[\mathrm{M}_{\mathrm{i}}\right]$ on diagonal and $\varepsilon$ elsewhere. $\left[\mathrm{M}_{\mathrm{i}}\right]$ is defined by:

$$
\left[\mathrm{M}_{\mathrm{i}}\right]=\left[\begin{array}{cccc}
\mathcal{E} & \mathcal{\varepsilon} & \mathcal{\varepsilon} & \tau_{i, 3} \\
\mathcal{E} & \mathcal{E} & \mathcal{\varepsilon} & \tau_{i, 1} \tau_{i, 3} \Delta x_{i, 2} \\
\mathcal{E} & \mathcal{E} & \mathcal{E} & \tau_{i, 1} \tau_{i, 3} \Delta x_{i, 3} \\
\mathcal{E} & \mathcal{E} & \mathcal{\varepsilon} & \lambda_{i}
\end{array}\right]
$$

Like in the periodic case, the network evaluation (in terms of connection times) may be performed by solving this $(\max ,+)$ model $(15)$. For this goal, we use an iterative algorithm to arbitrate the identified conflicts on the model Nait et al, (2006). For each iteration, the algorithm principle consists in firing each transition $\mathrm{x}_{\mathrm{i}, \mathrm{j}}$ in conflict situation and for which all upstream places $\left(\forall \mathrm{P} \in \mathrm{C}_{\mathrm{i}, \mathrm{j}}\right.$ ) contain at least one token; in this case, $\mathrm{x}_{\mathrm{i}, \mathrm{j}}$ is said to be really fired $\left(x_{i, j}(k) \neq \varepsilon\right)$. Otherwise, if the marking of at least one of these places is empty, $x_{i, j}$ will not be fired; we say that the transition is virtually fired $\left(x_{i, j}(k)=\varepsilon\right)$. The routing policy proposed ensures the model liveliness. The algorithm used enables us to find various values of routing functions $\Delta \mathrm{x}_{\mathrm{i}, \mathrm{j}}(\mathrm{k})$ for all $\mathrm{k} \geq 1$. 
The following section shows that the analysis of this model based on spectral theory also may provide interesting results, in the form of the expression of eigenvalues and eigenvectors according to the problem parameters. Nevertheless, the relaxation of the periodicity constraint makes the interpretation difficult for the performance evaluation.

\subsection{Eigenvalues and eigenvectors}

To find these elements we follow the same method used in the periodic working mode. So we consider the precedence graph $\mathrm{G}(\mathrm{M})$ (figure 5) from which we obtain all eigenvalues.
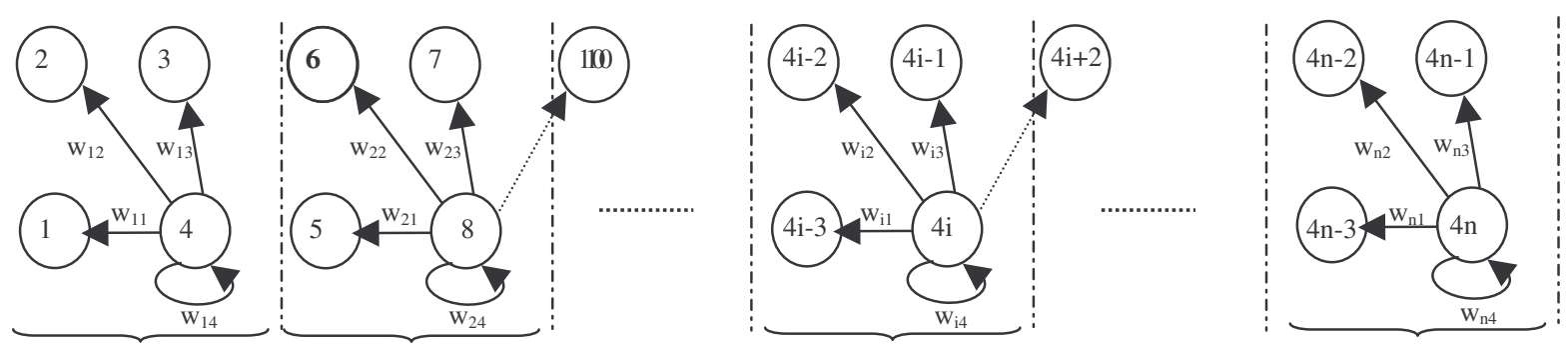

For $\mathrm{i}=1$ to $\mathrm{n}, \quad \mathrm{w}_{\mathrm{i} 1}=\mathrm{a}_{4 \mathrm{i}-3,4 \mathrm{i}}=\tau_{\mathrm{i}, 3} ; \mathrm{w}_{\mathrm{i} 2}=\mathrm{a}_{4 \mathrm{i}-2,4 \mathrm{i}}=\tau_{\mathrm{i}, 1} \tau_{\mathrm{i}, 3} \Delta \mathrm{x}_{\mathrm{i}, 2} ; \mathrm{w}_{\mathrm{i} 3}=\mathrm{a}_{4 \mathrm{i}-1,4 \mathrm{i}}=\tau_{\mathrm{i}, 1} \tau_{\mathrm{i}, 3} \Delta \mathrm{x}_{\mathrm{i}, 3} ;$ and $\mathrm{w}_{\mathrm{i} 4}=\mathrm{a}_{4 \mathrm{i}, 4 \mathrm{i}}=\lambda_{\mathrm{i}}$ (where $\mathrm{a}_{\mathrm{ij}}$ is the weight associated with each $\operatorname{arc} \mathrm{j} \rightarrow \mathrm{i}$ ).

Figure 5. Precedence graph of the matrix M: non periodic working mode.

Like in figure 3, the matrix associated with this graph contains $\mathrm{n}$ eigenvalues $\operatorname{Sp}(\mathrm{M})=\left\{\lambda_{1}, \lambda_{2}, \ldots . \lambda_{\mathrm{n}}\right\}$. For the elementary network given by figure 4 , we obtain the eigenvalues $\left(\lambda_{\mathrm{i}}, \lambda_{\mathrm{i}+1}\right)=\left(\operatorname{Sp}\left(\left[\mathrm{M}_{\mathrm{i}}\right]\right), \operatorname{Sp}\left(\left[\mathrm{M}_{\mathrm{i}+1}\right]\right)\right)$.

To obtain the eigenvector associated with $\left[\mathrm{M}_{\mathrm{i}+1}\right]$, we follow the same method given in the previous paragraph. We try to solve the equation:

$$
\left[\mathrm{M}_{\mathrm{i}+1}\right] \otimes \mathrm{V}^{\lambda_{\mathrm{i}+1}}(\mathrm{k})=\lambda_{\mathrm{i}+1} \otimes \mathrm{V}^{\lambda_{\mathrm{i}+1}}(\mathrm{k})
$$

where $\left(\lambda_{i+1}, V\right) \neq(\varepsilon, \varepsilon)$ and $V$ is the associated eigenvector to $\lambda_{i+1}$.

Let us put $\mathrm{V}=\left[\mathrm{v}_{\mathrm{i}+1,1}, \mathrm{v}_{\mathrm{i}+1,2}, \mathrm{v}_{\mathrm{i}+1,3}, \mathrm{v}_{\mathrm{i}+1,4}\right]$. Developing the equation (16) enables us to obtain the following system (without loss of generality, we consider only the connection between the two lines $\mathrm{L}_{\mathrm{i}}$ and $\left.\mathrm{L}_{\mathrm{i}+1}\right)$ :

$$
\left\{\begin{array}{l}
\mathrm{v}_{\mathrm{i}+1,1}=\left(\mathrm{e} / \tau_{\mathrm{i}+1,1} \tau_{\mathrm{i}+1,2}\right) \otimes \mathrm{v}_{\mathrm{i}+1,4} \\
\mathrm{v}_{\mathrm{i}+1,2}=\left(\Delta \mathrm{x}_{\mathrm{i}+1,2}(\mathrm{k}) / \tau_{\mathrm{i}+1,2}\right) \otimes \mathrm{v}_{\mathrm{i}+1,4} \\
\mathrm{v}_{\mathrm{i}+1,3}=\left(\Delta \mathrm{x}_{\mathrm{i}+1,3}(\mathrm{k}) / \tau_{\mathrm{i}+1,2}\right) \otimes \mathrm{v}_{\mathrm{i}+1,4}
\end{array}\right.
$$

where " /" represents the subtraction in $(\max ,+)$ algebra $(\mathrm{a} / \mathrm{b}=\mathrm{a}-\mathrm{b}$ in usual algebra).

From these equations the associated eigenvector $V$ to eigenvalue $\lambda_{i+1}$ can be expressed by: 


$$
\begin{aligned}
\mathrm{V}^{\lambda_{\mathrm{i}+1}(\mathrm{k})}= & <\operatorname{Vect}\left(\lambda_{\mathrm{i}+1}\right)> \\
= & {\left[\left(\mathrm{e} / \tau_{\mathrm{i}+1,1} \tau_{\mathrm{i}+1,2}\right) \mathrm{v}_{\mathrm{i}+1,4},\left(\Delta \mathrm{x}_{\mathrm{i}+1,2}(\mathrm{k}) / \tau_{\mathrm{i}+1,2}\right) \mathrm{v}_{\mathrm{i}+1,4},\left(\Delta \mathrm{x}_{\mathrm{i}+1,3}(\mathrm{k}) / \tau_{\mathrm{i}+1,2}\right) \mathrm{v}_{\mathrm{i}+1,4}, \mathrm{v}_{\mathrm{i}+1,4}\right] } \\
& =\mathrm{v}_{\mathrm{i}+1,4} \otimes\left[\left(\mathrm{e} / \tau_{\mathrm{i}+1,1} \tau_{\mathrm{i}+1,2}\right),\left(\Delta \mathrm{x}_{\mathrm{i}+1,2}(\mathrm{k}) / \tau_{\mathrm{i}+1,2}\right),\left(\Delta \mathrm{x}_{\mathrm{i}+1,3}(\mathrm{k}) / \tau_{\mathrm{i}+1,2}\right), \mathrm{e}\right]
\end{aligned}
$$

with $\mathrm{v}_{\mathrm{i}+1,4} \in \mathbb{R}_{\max }$.

From the expression (18) we remark that $\left\langle\operatorname{Vect}\left(\lambda_{i+1}\right)\right\rangle$ depends on the two cases : connection or not between $\mathrm{L}_{\mathrm{i}}$ and $\mathrm{L}_{\mathrm{i}+1}$. We now describe these two possible cases and we try to identify $<\operatorname{Vect}\left(\lambda_{\mathrm{i}+1}\right)>$.

- Case $\mathrm{N}^{\circ} 1$ : a connection is really carried out

Using the expression of the routing functions $\Delta \mathrm{x}_{\mathrm{i}+1,2}(\mathrm{k})$ and $\Delta \mathrm{x}_{\mathrm{i}+1,3}(\mathrm{k})$ when a connection $\mathrm{k}(\forall \mathrm{k}>1)$ is carried out between $\mathrm{L}_{\mathrm{i}}$ and $\mathrm{L}_{\mathrm{i}+1}$, we can write $\Delta \mathrm{x}_{\mathrm{i}+1,2}(\mathrm{k})=\mathrm{e}$ and $\Delta \mathrm{x}_{\mathrm{i}+1,3}(\mathrm{k})=\varepsilon$. So we obtain:

$$
\begin{aligned}
<\operatorname{Vect}\left(\lambda_{\mathrm{i}+1}\right)> & =\mathrm{v}_{\mathrm{i}+1,4} \otimes\left[\left(\mathrm{e} / \tau_{\mathrm{i}+1,1} \tau_{\mathrm{i}+1,2}\right),\left(\mathrm{e} / \tau_{\mathrm{i}+1,2}\right), \varepsilon, \mathrm{e}\right] \\
& =\mathrm{v}_{\mathrm{i}+1,4}\left[-\left(\tau_{\mathrm{i}+1,1}+\tau_{\mathrm{i}+1,2}\right),-\tau_{\mathrm{i}+1,2}, \varepsilon, \mathrm{e}\right]
\end{aligned}
$$

If we choose $v_{i+1,4}=\lambda_{i+1}$, then: $\left\langle\operatorname{Vect}\left(\lambda_{i+1}\right)\right\rangle=\left[\tau_{i+1,3}, \tau_{i+1,1}+\tau_{i+1,3}, \varepsilon, \lambda_{i+1}\right]$

- Case $\mathrm{N}^{\circ} 2$ : no connection is carried out

For this case we write $\Delta \mathrm{x}_{\mathrm{i}+1,2}(\mathrm{k})=\varepsilon$ and $\Delta \mathrm{x}_{\mathrm{i}+1,3}(\mathrm{k})=\mathrm{e}$. So with $\mathrm{v}_{\mathrm{i}+1,4}=\lambda_{\mathrm{i}+1}$, eigenvector will be: $\left\langle\operatorname{Vect}\left(\lambda_{\mathrm{i}+1}\right)\right\rangle=\left[\tau_{\mathrm{i}+1,3}, \varepsilon, \tau_{\mathrm{i}+1,1}+\tau_{\mathrm{i}+1,3}, \lambda_{\mathrm{i}+1}\right]$.

$\mathrm{V}^{\lambda_{i+1}}$ depends on routing equations, then its general expression is initially given according to the parameter $\mathrm{k}$. But in each considered case, the instantiation of the routing functions with constant values, involves that the obtained eigenvector $\mathrm{V}^{\lambda_{i+1}}$ does not evolve with time. So, in practice, this prevents us from evaluating the waiting times of passengers in connection stops using theory spectral elements. Nevertheless, the proposed routing policy for the non periodic working mode allows us to easily solve and arbitrate identified conflicts. And a classical solving of the associated state model leads to determine the connection times Nait et al. (2006). Finally this first study could lead to further researches about the expression and interpretation of eigenvectors.

\section{Numerical example}

In this example, we generalise the obtained results in the periodic working mode considering several buses circulating on each network line. We consider a public 
transportation network composed of three lines and two connection stops. The second line $\left(\mathrm{L}_{2}\right)$ has two common connection stops respectively with the line $\mathrm{L}_{1}\left(\mathrm{Cs}_{1,2}\right)$ and the line $\mathrm{L}_{3}$ $\left(\mathrm{Cs}_{2,3}\right)$. The actual moving times between two stops $\tau_{\mathrm{i}, 1}, \tau_{\mathrm{i}, 2}$ and $\tau_{\mathrm{i}, 3}$, the necessary time to perform a round of each line $\lambda_{\mathrm{i}}=\tau_{\mathrm{i}, 1}+\tau_{\mathrm{i}, 2}+\tau_{\mathrm{i}, 3}$ (period) and the number of buses circulating of each line are given in Table I.

Table I: Network data

\begin{tabular}{|c|c|c|c|c|c|c|}
\hline line $\mathrm{L}_{\mathrm{i}}$ & number of buses & & data & $(\min )$ & & \\
\hline \multirow[t]{2}{*}{$\mathrm{L}_{1}$} & \multirow[t]{2}{*}{$\mathrm{N}\left(\mathrm{B}_{1}\right)=3$} & for $\mathrm{N}\left(\mathrm{B}_{1}\right)$ buses & $\lambda_{1}=15$ & $\tau_{1,1}=3$ & $\tau_{1,2}=3$ & $\tau_{1,3}=9$ \\
\hline & & for one bus & $\beta_{1}=5$ & $\rho_{1,1}=1$ & $\rho_{1,2}=1$ & $\rho_{1,3}=3$ \\
\hline \multirow[t]{2}{*}{$\mathrm{L}_{2}$} & \multirow[t]{2}{*}{$\mathrm{N}\left(\mathrm{B}_{2}\right)=5$} & for $\mathrm{N}\left(\mathrm{B}_{2}\right)$ buses & $\lambda_{2}=35$ & $\tau_{2,1}=5$ & $\tau_{2,2}=10$ & $\tau_{2,3}=20$ \\
\hline & & for one bus & $\beta_{2}=7$ & $\rho_{2,1}=1$ & $\rho_{2,2}=2$ & $\rho_{2,3}=4$ \\
\hline \multirow[t]{2}{*}{$\mathrm{L}_{3}$} & \multirow[t]{2}{*}{$\mathrm{N}\left(\mathrm{B}_{3}\right)=3$} & for $\mathrm{N}\left(\mathrm{B}_{3}\right)$ buses & $\lambda_{3}=24$ & $\tau_{3,1}=6$ & $\tau_{3,2}=6$ & $\tau_{3,3}=12$ \\
\hline & & for one bus & $\beta_{3}=8$ & $\rho_{3,1}=2$ & $\rho_{3,2}=2$ & $\rho_{3,3}=4$ \\
\hline
\end{tabular}

The time reference equals to zero $(t=0)$, which corresponds to $6 \mathrm{~h} 00 \mathrm{~min}$. Buses of $\mathrm{L}_{1}$ (respectively of $\mathrm{L}_{2}$ and $\mathrm{L}_{3}$ ) make their departures from $\mathrm{Ds}_{1}$ (respectively from $\mathrm{Ds}_{2}, \mathrm{Ds}_{3}$ ) at each $5 \mathrm{~min}$ (respectively each $7 \mathrm{~min}$ and $8 \mathrm{~min}$ ). The first departures of the three buses from their departure stops $\mathrm{Ds}_{\mathrm{i}}$ respectively occur at times $\mathrm{t}=9(6 \mathrm{~h} 09 \mathrm{~min}), \mathrm{t}=15(6 \mathrm{~h} 15 \mathrm{~min})$ and $\mathrm{t}=12$ (6h12min). Besides we consider three possible destinations on each line $\mathrm{As}_{1}, \mathrm{As}_{2}, \mathrm{As}_{3}$. The moving times $d_{i}$ between the stops $C s_{i+1}$ and $A s_{i}$ (for $1 \leq i \leq 2$ ) are respectively: $d_{1}=2, d_{2}$ $=5$ and $\mathrm{d}_{3}=3 \mathrm{~min}$.

Studying a line whose period equals to $\lambda_{i}$ and which is served by $N\left(B_{i}\right)$ buses $\left(N\left(B_{i}\right) \neq\right.$ $1)$ is equivalent to studying a line whose period equals $\lambda_{i}$ divided by $N\left(B_{i}\right)\left(\lambda_{i} \div N\left(B_{i}\right)\right)$ and which is served with a single bus. In this case, the real period, called $\beta_{\mathrm{i}}$, of line $\mathrm{L}_{\mathrm{i}}$ becomes $\beta_{\mathrm{i}}=\lambda_{\mathrm{i}} \div \mathrm{N}\left(\mathrm{B}_{\mathrm{i}}\right)$, and the actual moving times of buses become: $\rho_{\mathrm{i}, 1}=\tau_{\mathrm{i}, 1} \div \mathrm{N}\left(\mathrm{B}_{\mathrm{i}}\right), \rho_{\mathrm{i}, 2}=\tau_{\mathrm{i}, 2} \div$ $\mathrm{N}\left(\mathrm{B}_{\mathrm{i}}\right)$ and $\rho_{\mathrm{i}, 3}=\tau_{\mathrm{i}, 3} \div \mathrm{N}\left(\mathrm{B}_{\mathrm{i}}\right)$. Then we write $\beta_{\mathrm{i}}=\rho_{\mathrm{i}, 1}+\rho_{\mathrm{i}, 2}+\rho_{\mathrm{i}, 3}$.

Serving each network line with several buses changes the graph marking of figure 2, which changes the expression of the associated state model. Nevertheless, if we replace the old data $\left(\lambda_{i}, \tau_{i, 1}, \tau_{i, 2}, \tau_{i, 3}\right)$ with the new data $\left(\beta_{i}, \rho_{i, 1}, \rho_{i, 2}, \rho_{i, 3}\right)$, the system study remains the same given previously. So, the system (2) describing the considered elementary network (three lines) remains the same one. 
Using the spectral theory of the characteristic matrix developed previously (system (2) with $\mathrm{n}=3$ lines), the three eigenvalues of the matrix $\mathrm{A}(\mathrm{k}-1)$ are $\{15 \div 3=5,35 \div 5=7$, $24 \div 3=8\}$. These values represent the new periods of lines $L_{1}, L_{2}$ and $L_{3}$ respectively; the eigenvectors associated with these eigenvalues are the following ones:

$$
\begin{aligned}
& \mathrm{V}^{5}(\mathrm{k})=\left[\mathrm{e}, \varepsilon, 2,3, \varepsilon, 2 \otimes 5^{(\mathrm{f} 2,4(\mathrm{k}) / \mathrm{k})}, \varepsilon, \varepsilon, \varepsilon, \varepsilon, \varepsilon, \varepsilon\right]^{\mathrm{t}} ; \\
& \mathrm{V}^{7}(\mathrm{k})=\left[\varepsilon, \varepsilon, \varepsilon, \varepsilon, \mathrm{e}, 1 \otimes 7^{(\mathrm{f} 2,3(\mathrm{k}) / \mathrm{k})}, 1 \otimes 7^{(\mathrm{f} 2,6(\mathrm{k}) / \mathrm{k})}, 3, \varepsilon, 3 \otimes 7^{(\mathrm{f} 3,4(\mathrm{k}) / \mathrm{k})}, \varepsilon, \varepsilon,\right]^{\mathrm{t}} ; \\
& \mathrm{V}^{8}(\mathrm{k})=\left[\varepsilon, \varepsilon, \varepsilon, \varepsilon, \varepsilon, \varepsilon, \varepsilon, \varepsilon, \mathrm{e}, 2 \otimes 8^{(\mathrm{f} 3,3(\mathrm{k}) / \mathrm{k})}, 2 \otimes 8^{(\mathrm{f} 3,6(\mathrm{k}) / \mathrm{k})}, 4\right]^{\mathrm{t}} .
\end{aligned}
$$

where the routing functions are expressed as: $\forall \mathrm{k} \geq 1$, with $\mathrm{E}(\mathrm{x})$ is the integer part of $\mathrm{x}$.

$\mathrm{f}_{2,3}(\mathrm{k})=\mathrm{k} ; \mathrm{f}_{2,4}(\mathrm{k})=\mathrm{E}\left(\frac{7 k+3}{5}\right) ; \mathrm{f}_{2,6}(\mathrm{k})=\varepsilon$

$\mathrm{f}_{3,3}(\mathrm{k})=\mathrm{k}+1 ; \mathrm{f}_{3,4}(\mathrm{k})=\mathrm{E}\left(\frac{8 k-3}{7}\right) ; \mathrm{f}_{3,6}(\mathrm{k})=\left\{\begin{array}{cc}1 & \text { if } \\ \varepsilon & \text { othewise }\end{array}\right.$

These vectors enable us to provide the waiting time and the journey time of passengers who arrive at the departure stops $\mathrm{Ds}_{\mathrm{i}}$ for $1 \leq \mathrm{i} \leq 3$ at various times $\mathrm{T}$. We consider several passengers who want to make a travel from $\mathrm{Ds}_{1}$ to $\mathrm{As}_{3}$ for different times $\mathrm{T}$. In table II we expose the obtained results about waiting times at each connection stop (equation (10)) and

\begin{tabular}{|c|c|c|c|c|c|c|}
\hline \multirow[t]{2}{*}{$\begin{array}{l}\text { Departure time from } \\
\mathrm{Ds}_{1}\end{array}$} & \multirow[t]{2}{*}{$\begin{array}{l}\mathrm{m}^{\text {th }} \text { bus } \\
\mathrm{B}_{1}\end{array}$} & \multicolumn{2}{|c|}{$\begin{array}{l}\text { Connection } \\
\mathrm{L}_{1} \text { to } \mathrm{L}_{2}\end{array}$} & \multicolumn{2}{|c|}{$\begin{array}{l}\text { Connection } \\
\mathrm{L}_{2} \text { to } \mathrm{L}_{3}\end{array}$} & \multirow{2}{*}{$\begin{array}{l}\mathrm{T}_{\text {journey }}(1,3, \mathrm{~T})= \\
\mathrm{T}_{1,2}+\mathrm{T}_{2,3}+\rho_{1,1}+ \\
\rho_{1,2}+\rho_{2,2}+d_{3}\end{array}$} \\
\hline & & $\mathrm{k}^{\text {th }}$ bus $\mathrm{B}_{2}$ & $\mathrm{~T}_{1,2}(\mathrm{~m}, \mathrm{k})$ & $\mathrm{k}^{\text {,th }}$ bus $\mathrm{B}_{3}$ & $\mathrm{~T}_{2,3}\left(\mathrm{~m}, \mathrm{k}^{\prime}\right)$ & \\
\hline $\mathrm{T}=14(\approx 6 \mathrm{~h} 14 \mathrm{~min})$ & $\mathrm{m}=2$ & 1 & 1 & 2 & 5 & 13 \\
\hline $\mathrm{T}=109(\approx 7 \mathrm{~h} 49 \mathrm{~min})$ & $\mathrm{m}=21$ & 15 & 4 & 14 & 3 & 14 \\
\hline $\mathrm{T}=154(\approx 8 \mathrm{~h} 34 \mathrm{~min})$ & $\mathrm{m}=30$ & 21 & 1 & 19 & 1 & 9 \\
\hline $\mathrm{T}=169(\approx 8 \mathrm{~h} 49 \mathrm{~min})$ & $\mathrm{m}=33$ & 23 & 0 & 21 & 3 & 10 \\
\hline $\mathrm{T}=184(\approx 9 \mathrm{~h} 04 \mathrm{~min})$ & $m=36$ & 26 & 1 & 24 & 6 & 14 \\
\hline $\mathrm{T}=189(\approx 9 \mathrm{~h} 09 \mathrm{~min})$ & $\mathrm{m}=37$ & 26 & 1 & 24 & 6 & 14 \\
\hline $\mathrm{T}=244(\approx 10 \mathrm{~h} 04 \mathrm{~min})$ & $\mathrm{m}=48$ & 34 & 2 & 31 & 6 & 15 \\
\hline
\end{tabular}
different travel times (equation (12)) of passengers coming from $\mathrm{Ds}_{1}$ to $\mathrm{As}_{3}$.

Table II: Waiting times and travel times of some passengers obtained using spectral theory. 
The results obtained with spectral theory are similar to those obtained by solving the state model, but with a small restriction already detailed in section 5.2, that can be extended with parameters $\beta_{\mathrm{i}}$ (instead of $\lambda_{\mathrm{i}}$ ): if $\beta_{\mathrm{i}}<\beta_{\mathrm{i}+1}$ and if several batches of passengers successively arrive on buses of line $\mathrm{L}_{\mathrm{i}}$ between two arrivals of buses of line $\mathrm{L}_{\mathrm{i}+1}$, the proposed method only enables us to define the waiting time of the last batch arriving at the connection stop. The waiting times of other batches are supposed to be similar to the calculated one. For example, in table II and for $\mathrm{T}=184: \mathrm{T}_{1,2}(184,36,26)=\mathrm{T}_{1,2}(189,37,26)=1 \mathrm{~min}$. But we should find $\mathrm{T}_{1,2}(184,36,26)=6 \mathrm{~min}$.

\section{Conclusion}

In this paper we described the modelling and the evaluation of a public transport network, in a first time, with a subclass of Petri Nets called dynamic timed event graph with withdrawal of tokens, and in a second time with the mathematical approach $(\max ,+)$ algebra. Those tools enabled us to model our transportation network, whatever the working mode of the bus lines is: synchronized or not at the connection stops, periodic or not. The obtained mathematical formulation corresponding to the Petri net model was given as a non-stationary $(\max ,+)$ linear state representation, due to structural conflicts appearing in the graph. Those conflicts were arbitrated by different methods according to the operating mode.

For each considered mode, we discussed some properties of the spectral theory of a matrix in $(\max ,+)$ algebra. We showed that our analysis approach with spectral theory is adapted for performance evaluation of bus networks (in terms of connection times), especially in the periodic mode. One of its advantages is that it does not require to solve the $(\max ,+)$ model. This approach certainly may be improved to obtain similar results for the non periodic working mode. This last aspect is the first prospect of this work. Another prospect is the extension of the obtained results to more complex transport systems (for example multimodal networks). We also aim at developing the spectral theory to propose a control that ensures a good management of buses on the network and minimum waiting times of passengers.

\section{References}

- Baccelli F, Cohen G, Olsder G-J, Quadrat J-P. Synchronisation and linearity, Algebra for discrete Event Systems. John Wiley et Sons; 1992. 
- Böcker J, Lind J, Zirkler B. Using a multi-agent approach to optimise the train coupling and sharing system. European Journal of Operational Research 2001; 134; 242-252.

- Braker J-G. Max-algebra modelling and analysis of time-table dependent transportation networks. Proceedings of the First European Control Conference (ECC'91). France; Grenoble; 1991; 1831-1836.

- Bussieck, Michael R, Winter T, Zimmermann, Uwe T. Discrete optimization in public rail transport. Mathematical Programming 1997; 79; 3; 415-444.

- Castelain E, Mesghouni K. Regulation of a Public Transport Network with consideration of the passenger flow: modeling of the system with High-level Petri Nets. Proceedings of the IEEE International Conference on Systems, Man and Cybernetics (IEEE SMC'02). Tunisia; Hammamet; 2002; 6; 250-254.

- Cohen G, Dubois D, Quadrat J-P, Viot M. A linear-system-theoretic view of discrete-event process and its use for performance evaluation in manufacturing. IEEE Transaction on Automatic Control $1985 ; 30 ; 3 ; 210-220$.

- Commission des Communautés Européennes. Politique européenne des transports à l'horizon 2010. Livre Blanc, Bruxelles 2001.

- David R, Alla H. Du grafcet aux réseaux de Petri. Paris : Hermès; 1992.

- De Schutter B. Max-Algebra system theory for discrete event systems. Ph.D thesis of Katholieke Universiteit Leuven Heverlee 1996.

- De Vries R, De Schutter B, De Moor B. On max-algebraic models for transportation Networks. Proceedings of the International Workshop on Discrete Event Systems (WODES'98). Italy; Cagliari; 1998; 457-462.

- Dridi M, Mesghouni K, Borne P. Traffic control in transportation systems. Journal of Manufacturing Technology Management 2005; 16; 1; 53-74.

- Di Febbraro A, Sacone S. Hybrid Modelling of Transportation Systems by means of Petri Nets. Proceedings of the IEEE International Conference on Systems, Man and Cybernetics (SMC'98). 1998; 1; 131-135.

- Gaubert S. Théorie des systèmes linéaires dans les dioïdes. PhD dissertation, Ecole Nationale Supérieure des Mines de Paris, 1992.

- Gaubert S. Systèmes dynamiques à événements discrets. Lecture notes, ENSMP, Automation and Master degree ATS Orsay, INRIA. France: Rocquencourt ; 1999.

- Gaujal B. Parallélisme et simulation des systèmes à événements discrets. PhD dissertation, University of Nice-Sophia Antipolis, 1994. 
- Houssin L, Lahaye S, Boimond J-L. Timetable synthesis using (max, +) algebra. Proceeding of the 12th IFAC Symposium Information Control Problems in Manufacturing. France; StEtienne; 2006; 375-380.

- Karlaftis M, Kepaptsoglou K, Stathopoulos A. Decision Support Systems For Planning Bus Operations During Mega Events: The Athens 2004 Summer Olympics. Proceeding of the 11th IFAC Symposium on Control in Transportation Systems. The Netherlands; Delft; 2006. CDROM (189).

- Lahaye S. Contribution à l'étude des systèmes linéaires non stationnaires dans l'algèbre des dioïdes. Ph.D. thesis in Engineering Sciences University of Angers 2000.

- Lahaye S, Boimond J-L, Hardouin L. GET avec ajout/retrait dynamique de jetons: comportement asymptotique représentation dans l'algèbre (min, +). Modélisation des systèmes réactifs (MSR'99). France ; Cachan ; 1999 ; 27-37.

- Nait-Sidi-Moh A. Modélisation et commande de systèmes de transport avec l'algèbre des dioïdes. $\mathrm{PhD}$ thesis in Automation and Computer Science, University of Franche-Comté, Belfort, december 2003.

- Nait-Sidi-Moh A, Manier, M-A, Manier H, El Moudni A. A (max, plus) modelling approach for the evaluation of travelling times in a public transportation system. Proceedings of the IEEE International Conference on Systems, Man and Cybernetics (SMC'02). Tunisia; Hammamet; 2002; 3; CD-ROM ISBN: 2-9512309-4-X.

- Nait-Sidi-Moh A, Manier M-A, El Moudni A. A (max, plus) algebra modelling approach to control a public transportation network constrained by maximal connection times. Proceedings of the International Multiconference on Computational Engineering in Systems Application (CESA’2003). France; Lille; 2003; CD-ROM ISBN: 2-9512309-5-8.

- Nait Sidi Moh A, Manier M-A, Manier H, El Moudni A. A max-plus algebra Modeling for a Public Transport System. Journal of Cybernetics and Systems 2005; 36; 2; 165-180.

- Nait-Sidi-Moh A, Manier M-A, El Moudni A, Wack M. Petri net with conflicts and (max, plus) algebra for transportation systems. Proceedings of the 11th IFAC Symposium on Control in Transportation Systems. The Netherlands; Delft; 2006; CD-ROM.

- Olsder G-J, Subiono S, Gettrick M-M. On large scale max-plus algebra model in railway systems. $26^{\text {ème }}$ école de printemps d'informatique, Algèbre $(\operatorname{Max},+)$ et applications en informatique ; France ; Ile de Noirmoutier; 1998 ; 177-192.

- Spacek P, Manier M-A, El Moudni A. Control of an electroplating line in the Max and Min algebras. International Journal of Systems Science 1999; 30; 7; 759-778. 
- Wang J, Jin C, Deng Y. Performance Analysis of Traffic Networks Based on Stochastic timed Petri Net Models. Proceedings of the $5^{\text {th }}$ IEEE International Conference on Engineering of Complex Computer Systems. 1999a; 77-85.

- Wang J, Jin C, Deng Y. Hybrid Genetic algorithm in solving vehicle routing problems with time windows constraints. Proceedings of the $23^{\text {th }}$ Annual International Computer Software and Applications Conference (COMPSA'99), 1999b; 436-441. 